\title{
Generation of Heteroatom Stereocenters by Enantioselective C-H Functionalization
}

\author{
Johannes Diesel and Nicolai Cramer*
}

Laboratory of Asymmetric Catalysis and Synthesis, Institute of Chemical Sciences and Engineering, Ecole Polytechnique Fédérale de Lausanne, EPFL SB ISIC LCSA, BCH 4305, CH1015 Lausanne, Switzerland

\begin{abstract}
C-H Functionalization has been established as an efficient way to generate molecular complexity. The formation of stereogenic carbon atoms by asymmetric $\mathrm{C}-\mathrm{H}$ functionalization has seen tremendous progress over the last decade. More recently, the direct catalytic modification of $\mathrm{C}-\mathrm{H}$ bonds has been powerfully applied to the formation of non-carbon stereogenic centers, which constitute a key design element of biologically active molecules and chiral ligands for asymmetric catalysis. This area was opened by a seminal report describing enantioselective $\mathrm{C}-\mathrm{H}$ functionalization for the formation of a silicon stereocenter. It rapidly expanded with advances in the enantioselective formation of phosphorus(V) centers. Moreover, enantioselective routes to chiral sulfur atoms in the oxidation state IV (sulfoxides) and VI (sulfoximines) have been disclosed. Herein, we discuss methods of using selective functionalization of $\mathrm{C}-\mathrm{H}$ bonds to generate a remote heteroatom stereogenic center via an inner-sphere $\mathrm{C}-\mathrm{H}$ activation mechanism.
\end{abstract}


KEYWORDS C-H Functionalization, Asymmetric Catalysis, Heteroatom Stereocenters, Heterocycles, Homogenous Catalysis

\section{INTRODUCTION}

The direct functionalization of unactivated carbon-hydrogen $(\mathrm{C}-\mathrm{H})$ bonds remains a challenge in organic synthesis and continues to give impetus for innovation in chemical reaction development. While the boundaries of what is considered an unactivated $\mathrm{C}-\mathrm{H}$ bond, translating to non-addressable by established methodologies, have been continuously pushed over the last decades, the task of selectivity plays an increasingly important role. ${ }^{1}$ Assembling chiral molecules by utilizing enantioselective functionalization of $\mathrm{C}-\mathrm{H}$ bonds has been established as an efficient way to generate molecular complexity. ${ }^{2}$ Tremendous progress has been achieved in the formation of stereogenic carbon atoms using asymmetric $\mathrm{C}-\mathrm{H}$ functionalization. Besides the well-known point chirality of the tetrahedral carbon atom, several heteroatoms can display stereogenicity Challenges in applying $\mathrm{C}-\mathrm{H}$ functionalization strategies used for the generation of carbon centered chirality to the synthesis of heteroatom stereocenters are associated with lower racemization barriers, in particular for nitrogen containing compounds and elongated carbon heteroatom bond lengths, as found for carbon phosphorus and carbon sulfur bonds, influencing the outcome of enantioselective transformations.

Heteroatom stereogenic compounds are present in a variety of naturally occurring compounds and also in pharmaceuticals and functional materials (Figure 1). ${ }^{3}$ Silicon stereocenters are not present in nature, but stereogenic silicon atoms are introduced in materials with unique physicochemical properties. ${ }^{4}$ Furthermore, the higher homologue germanium can be stereogenic. The group five element nitrogen displays stereogenicity if the rapid Walden inversion locked, as found in Tröger's 
Base. ${ }^{5}$ The higher homologue phosphorus has a significantly higher inversion barrier and stereogenic phosphor atoms are part of various bioactive compounds. ${ }^{6}$ Additionally, $P$-stereogenic ligand scaffolds are extensively used in asymmetric catalysis. ${ }^{7}$ Stereogenic sulfur atoms play an important role in general metabolism ${ }^{8}$ and an increasing number of new pharmaceuticals contain sulfur stereocenters. ${ }^{9}$

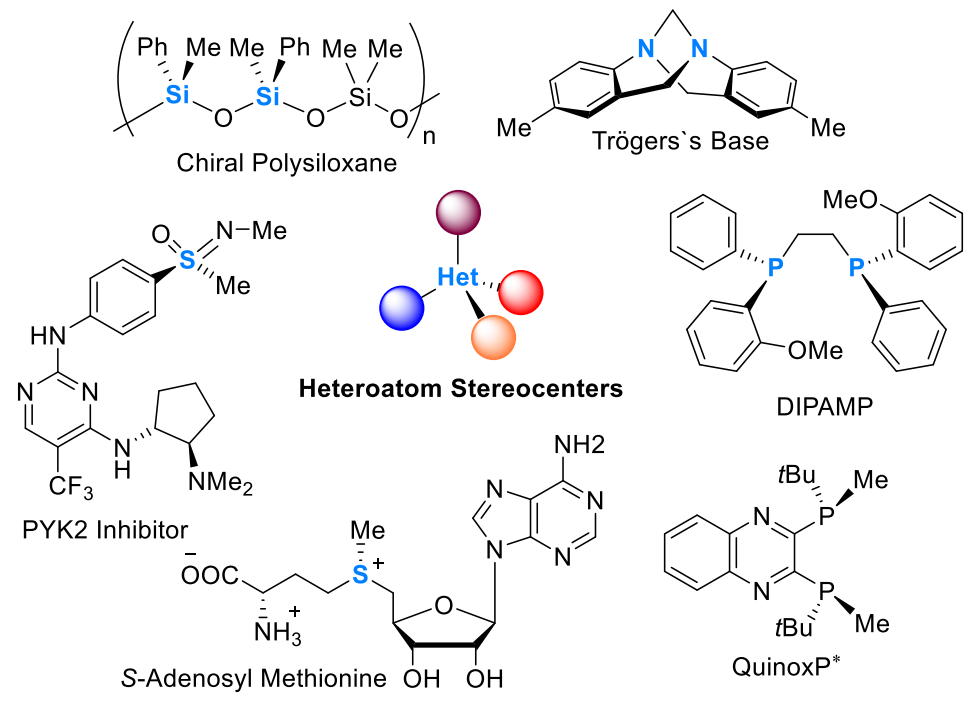

\section{Figure 1. Heteroatom Stereocenters in Bioactive Compounds and Fine Chemicals.}

Recently enantioselective $\mathrm{C}-\mathrm{H}$ functionalization has emerged as new tool to assemble these intriguing chiral compounds more efficiently. This review deals with enantioselective $\mathrm{C}-\mathrm{H}$ functionalizations to form heteroatom stereocenters operating via an inner-sphere type mechanism. $^{10}$

One approach to obtain heteroatom-centered chirality is the desymmetrizing $\mathrm{C}-\mathrm{H}$ activation of substrates with a prochiral heteroatom (Scheme 1). The functionality containing the heteroatom can be used as a directing group in combination with a transition metal catalyst to achieve desymmetrization (Scheme 1a). Organoheteroatom compound $\mathbf{1}$ is converted, in an enantiodetermining $\mathrm{C}-\mathrm{H}$ activation, to intermediate metallacycle 2, containing a heteroatom stereocenter. Subsequent inter- or intramolecular functionalization gives the chiral product 3. 
Conceptually different is the use of a prefunctionalized starting material, not relying on a directing group (Scheme 1b). Oxidative addition of a transition metal catalyst into the carbon(pseudo)halogen bond of $\mathbf{4}$ gives intermediate $\mathbf{5}$, which is converted in a enantiodetermining $\mathrm{C}-$ $\mathrm{H}$ activation to form metallacycle $\mathbf{6}$. Upon reductive elimination the chiral product 7 is released via formation of a five- or six membered ring.

a)

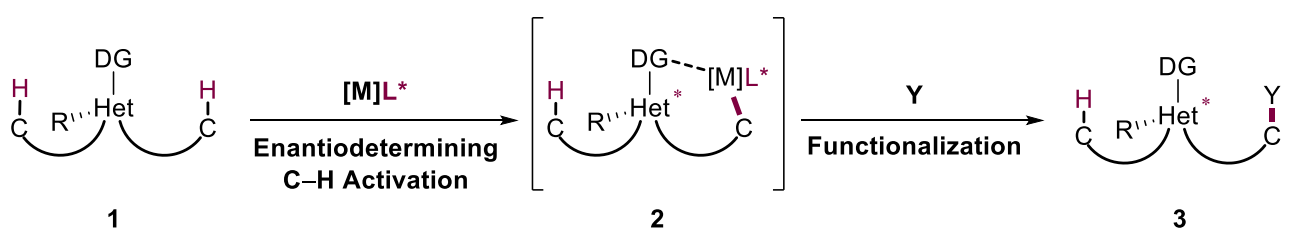

b)

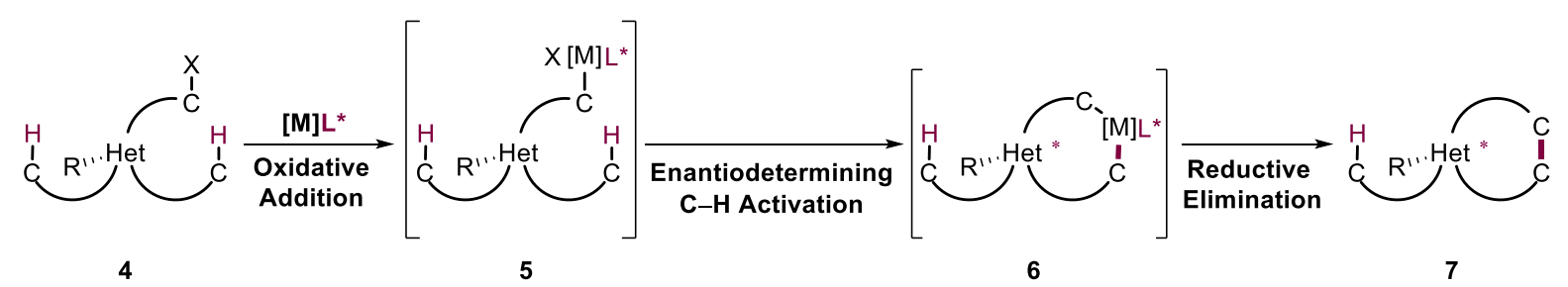

Scheme 1. Desymmetrization Approaches: a) Directing Group Mediated C-H Functionalization, b) Oxidative Addition, C-H Functionalization Sequence.

Additionally racemic heteroatom stereogenic starting materials can be applied in kinetic resolutions. Thereby overcoming the limitation of a symmetrically substituted starting material in the desymmetrization approach. Kinetic resolutions use chiral catalysts interacting differently with each substrate enantiomer (Scheme 2). The enantiomers $(S)-\mathbf{8}$ and $(R)-\mathbf{8}$ are recognized by a chiral catalyst resulting in different reaction rates for each enantiomer (Scheme 2a). ${ }^{11}$ One enantiomer reacts faster and forms the product $\mathbf{1 0}$ in maximum 50\% yield. The remaining starting material (S)-8 is in an ideal case reisolated in enantiopure form. A parallel kinetic resolution takes advantage of different chemo-, regio- or stereoselectivity for the reaction of each enantiomer of a racemic mixture with a reaction partner (Scheme $2 \mathrm{~b}$ ). ${ }^{12}$ The enantiomers $(S)$-11 and $(R)-\mathbf{1 1}$ are in this case 
converted to two different products. In the shown example, different regioselectivity is observed for each enantiomer and the products $\mathbf{1 4}$ and $\mathbf{1 5}$ can be obtained in maximum 50\% yield.

a)

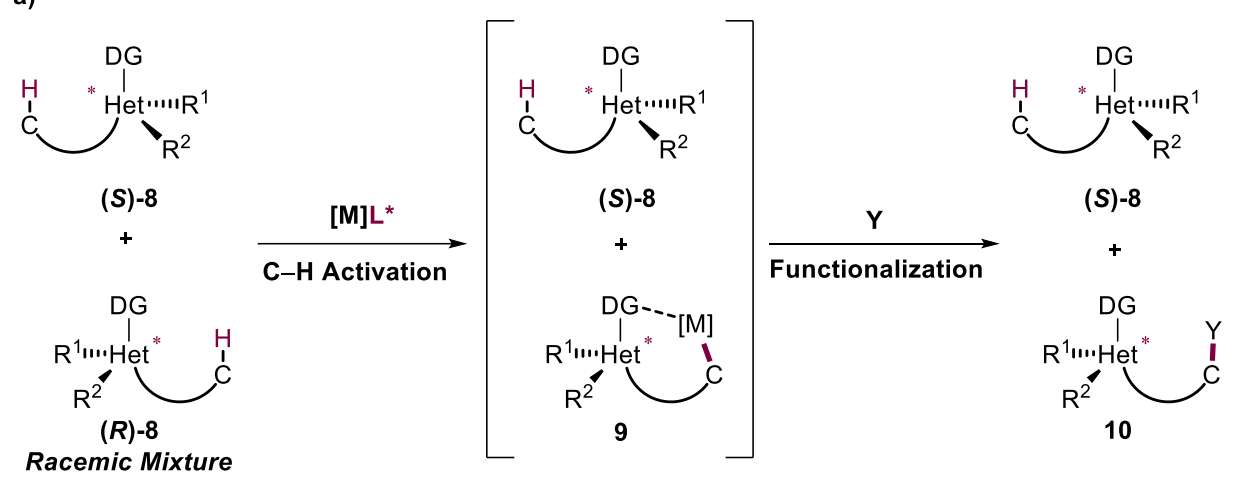

b)

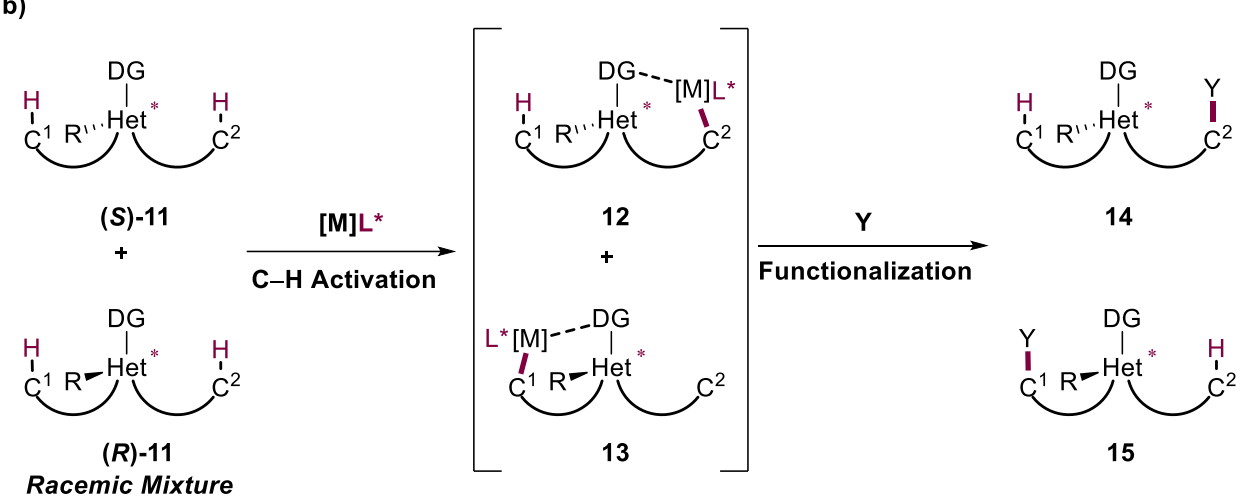

Scheme 2. Resolution Approaches for Enantioselective C-H Activation to Form Heteroatom Stereocenters: a) Kinetic Resolution, b) Parallel Kinetic Resolution.

The present review covers catalytic enantioselective $\mathrm{C}-\mathrm{H}$ functionalizations for the generation of heteroatom stereocenters until July 2019. We have grouped the reports by the formed stereogenic atom, which are the formation of stereogenic silicon, phosphorus and sulfur atoms. $\mathrm{C}-\mathrm{H}$ functionalization of heteroatom compounds, which rely on diastereoselective, auxiliary controlled transformations are beyond the scope of this review. Grouped information on this topic can be found in a review by $\mathrm{Cui}$ and $\mathrm{Xu} .^{13}$ 


\section{FORMATION OF SILICON STEREOCENTERS}

Silicon-containing molecules find wide application in a variety of materials. Large $\pi$-conjugated systems with unique optoelectronic properties allow applications as light-emitting diodes and solar

cells. ${ }^{4 a}{ }^{14}$ Furthermore, silicon is also introduced in bioactive compounds and marketed drugs. ${ }^{15}$ Acting as carbon isosteres organosilicon structures express unique physicochemical properties and potential medicinal applications. ${ }^{16}$ In contrast to ubiquitous carbon stereocenters found in biomolecules, silicon-stereogenic compounds are not present in nature and the synthesis of chiral organosilanes, containing a stereocenter at silicon has been a challenge. ${ }^{17}$ Over the last decade significant progress in development of catalytic asymmetric methodologies to form silicon stereocenters has been made, but the known strategies are still limited in number and generality. ${ }^{18}$ The application of $\mathrm{C}-\mathrm{H}$ functionalization strategies enabled more efficient access to silicon stereogenic compounds in a catalytic enantioselective way.

In 2012, Shintani, Hayashi and their co-workers reported the first catalytic enantioselective approach towards $\mathrm{Si}$-stereocenters applying functionalization of $\mathrm{C}\left(\mathrm{sp}^{2}\right)-\mathrm{H}$ bonds (Scheme 3). ${ }^{19}$ The work drew upon Shimizu's $\operatorname{Pd}(0) / \mathrm{Pd}(\mathrm{II})$-catalyzed approach to silicon-bridged biaryls. ${ }^{20} \mathrm{~A}$ PdJosiphos-type catalyst enabled the desymmetrization of triarylsilanes $\mathbf{1 6}$ to yield the siliconstereogenic dibenzosiloles $\mathbf{1 7}$ in high chemo- and enantioselectivity. The formation of the undesired achiral dibenzosilole $\mathbf{1 8}$ was largely suppressed by applying chiral bidentate phosphine ligand L1. Ortho-substituted substrates gave the products with high yield and enantioselectivity (17a and 17b). Additionally a tetraaryl silane was a competent substrate delivering the product 17c in $60 \%$ yield and $89 \%$ ee. Furthermore, a pathway for the formation of the undesired dibenzosilole 18 was proposed. The oxidative addition product $\mathbf{1 9}$ can undergo a 1,5-Pd migration to give $\mathbf{2 0}$. 
Both 19 and 20 undergo base-assisted intramolecular $\mathrm{C}-\mathrm{H}$ activation to yield different 6membered palladacycles 20 and $\mathbf{2 1}$, reductive elimination delivers the products 17a and $18 \mathbf{a}$.
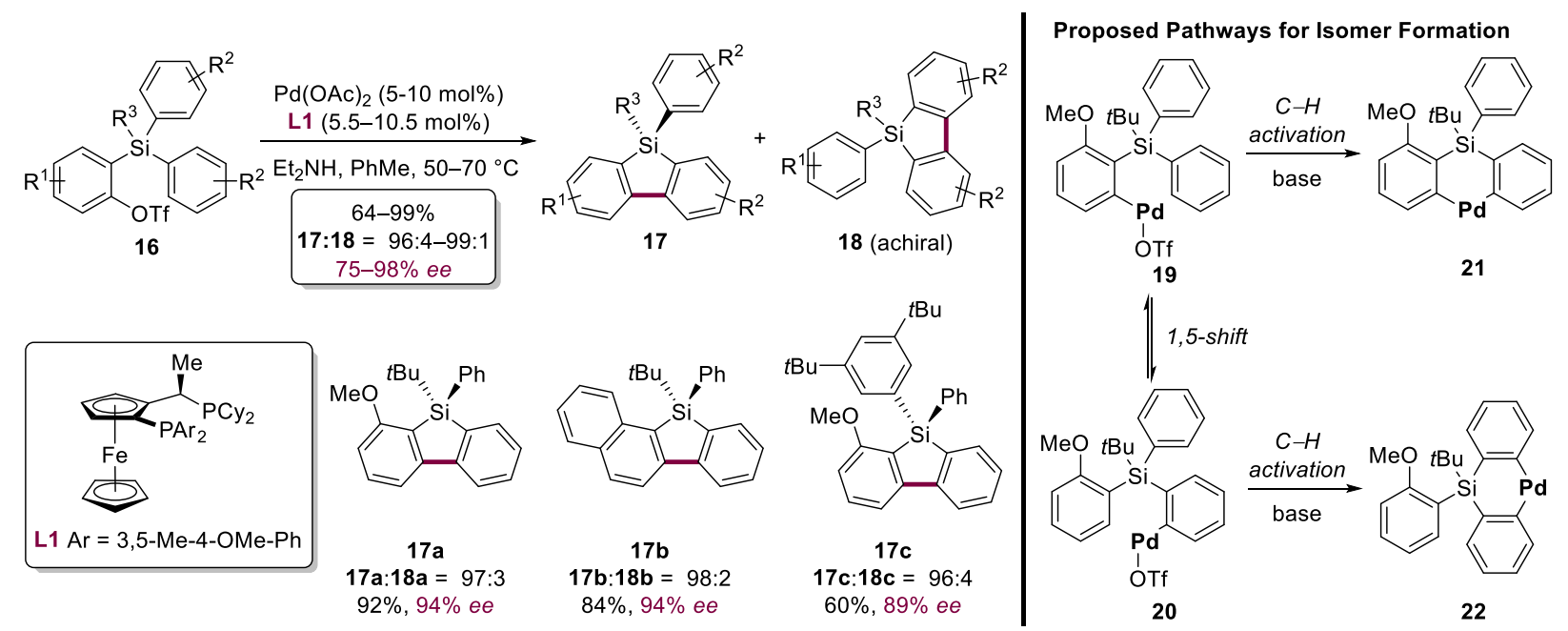

Scheme 3. Pd-Catalyzed Intramolecular C-H Functionalization Approach to Dibenzosiloles.

Building upon these findings Shintani, Nozaki and their co-workers utilized the 1,5-Pd migration to achieve enantioselective $\mathrm{C}-\mathrm{H}$ functionalization of 23. The application of a 4,4'-disubstituted BINAP ligand ${ }^{21}(R)-\mathbf{L} 2$ and $\mathrm{Pd}(\mathrm{OAc})_{2}$ enabled the formation of silicon-stereogenic 5,10-dihydrophenazasilines 24 in good yield and high enantioselectivity (Scheme 4). ${ }^{22}$ A variety of different aryl substituents were tolerated and the products were obtained in excellent enantioselectivity (e.g., 24a and 24b). Introducing a less bulky alkyl substituent on the silicon atom or the use of the corresponding secondary amine resulted in moderate selectivity (24c and $\mathbf{2 4 d}$ ). Mechanistic investigations suggested 1,5-Pd migration as the enantiodetermining step and deprotonation/reductive elimination sequence as turnover-limiting. 


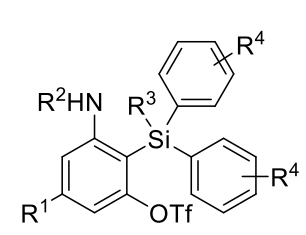

23

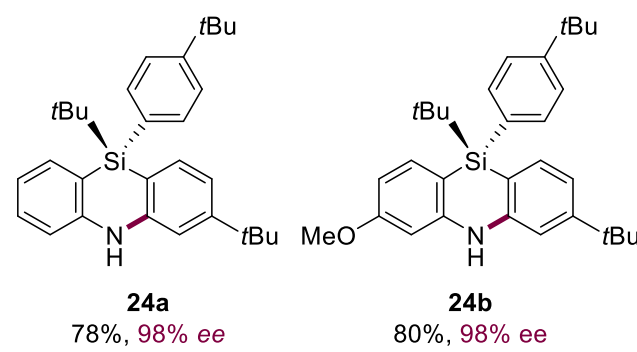

$\mathrm{Pd}(\mathrm{OAc})_{2}(5 \mathrm{~mol} \%)$ (R)-L2 (5.5 mol\%)

$\mathrm{Et}_{3} \mathrm{~N}, \mathrm{DMA}, 100^{\circ} \mathrm{C}$

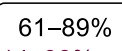

$14-98 \%$ ee

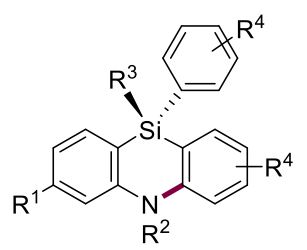

24
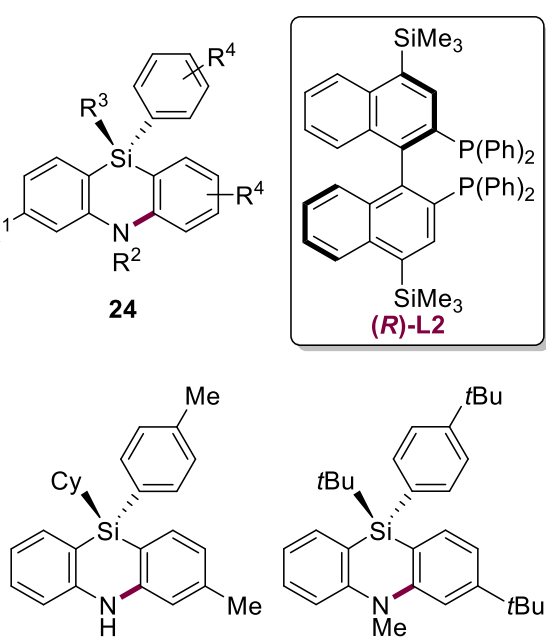

24c

$76 \%, 61 \%$ ee

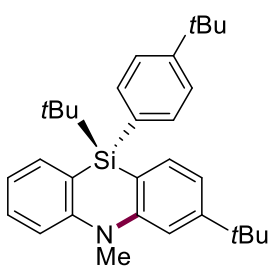

$6 \%, 75 \%$ ee

Scheme 4. Pd-Catalyzed Synthesis of 5,10-Dihydrophenazasilines via Enantioselective 1,5-Palladium Migration.

Recently Cui, $\mathrm{Xu}$ and their co-workers reported a $\mathrm{Pd}(\mathrm{II})$-catalyzed $\mathrm{C}-\mathrm{H}$ olefination of tetrasubstituted silanes (Scheme 5). ${ }^{23}$ The application of a silicon tethered pyridine directing group $^{24}$ enabled the $\mathrm{C}-\mathrm{H}$ desymmetrization of prochiral silanes $\mathbf{2 5}$ in good enantioselectivity. Intermolecular functionalization was achieved using $\mathrm{Pd}(\mathrm{OAc})_{2}$ and a survey of different monoprotected amino acids proved Fmoc-Phe-OH as optimal. ${ }^{25}$ Silanes containing bulky alkyl substituents were converted with different electron-deficient olefins 26 to obtain the siliconstereogenic products in moderate yield and good ee (e.g., 27a-c). In addition to methyl acrylate (e.g., 27a), styrenes (e.g., 27b) and acrylamides (e.g., 27c) were also suitable reaction partners. In general, substrates equipped with a quinoline directing group (e.g., 27c) were converted in higher ee. 


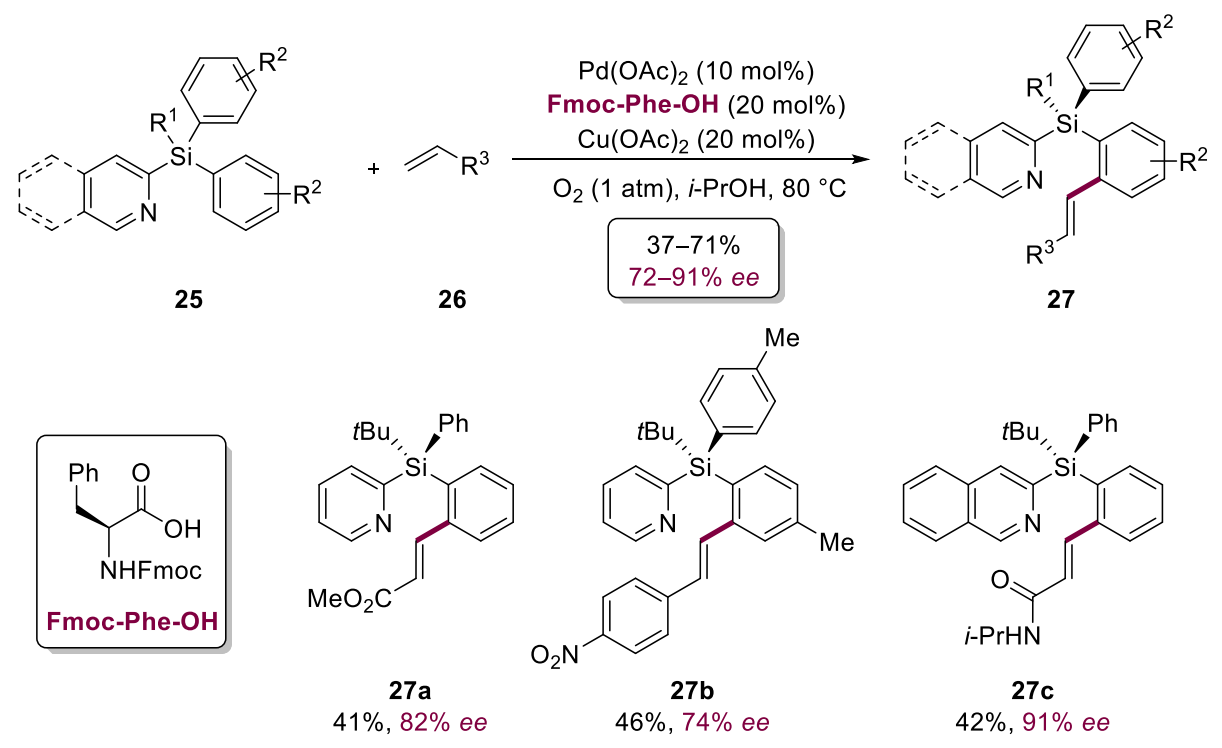

Scheme 5. Pd(II)-Catalyzed C-H Olefination of Tetrasubstituted Silanes.

In 2013, Kuninobu, Takai and their co-workers disclosed the Rh-catalyzed asymmetric synthesis of spirocyclic compounds with a quaternary silicon atom in high yield and enantioselectivity (Scheme 6). ${ }^{26}$ Cyclization of bis(biphenylsilanes) 28 using $[\mathrm{Rh}(\operatorname{cod}) \mathrm{Cl}]_{2}$ and $(R)$-BINAP delivered a silicon stereogenic intermediate, which is converted in a second $\mathrm{C}-\mathrm{H}$ functionalization to the axial chiral spirosilabifluorenes 29. Detailed mechanistic studies in collaboration with the Murai group included the isolation of intermediate $(R)-\mathbf{3 0 a}$ in $88 \%$ ee..$^{27}$ This could be converted under the same reaction conditions to the spirosilabifluorene $(R)$-29a without loss of ee, suggesting that the absolute configuration is determined in the first silylative cyclization. Intriguingly, the cyclization of 28a and $\mathbf{2 8 b}$ led to the same product enantiomer $(R)-29 \mathrm{a}$ in comparable yield and ee, highlighting that, in this case, the substitution pattern of the biphenyl moieties did not affect the enantioselectivity.
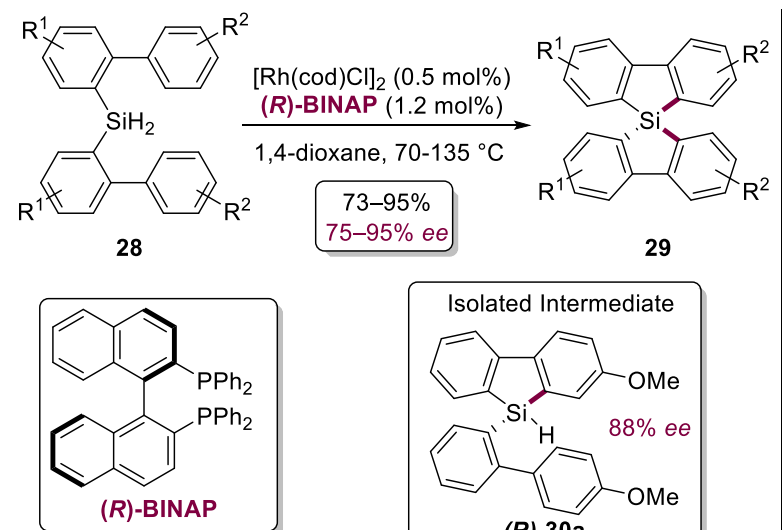

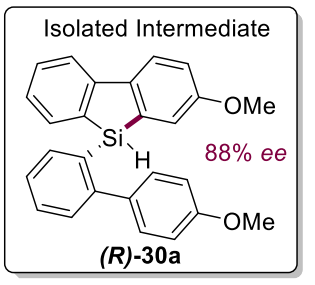

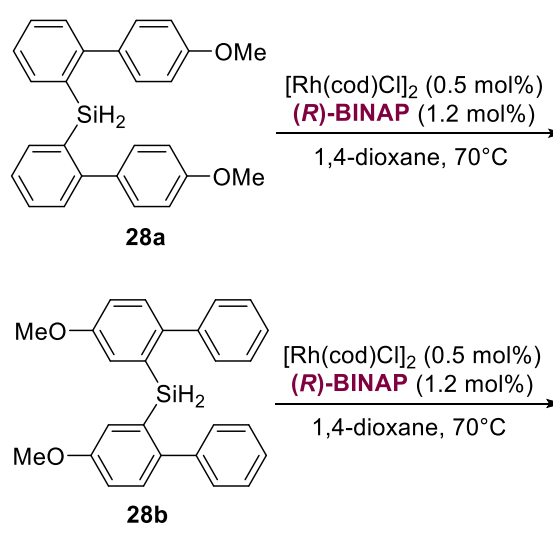

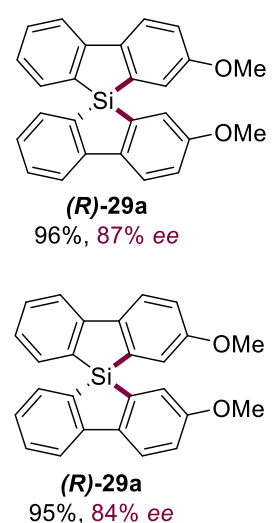




\section{Scheme 6. Rh-Catalyzed Asymmetric Synthesis of Spirosilabifluorenes.}

Takai, Murai and their co-workers extended this methodology for functionalization of more challenging $\mathrm{C}\left(\mathrm{sp}^{3}\right)-\mathrm{H}$ bonds, however only with poor enantiocontrol (Scheme 7) ${ }^{28}$ In a single example twofold dehydrogenative $\mathrm{C}\left(\mathrm{sp}^{3}\right)-\mathrm{H}$ bond silylation of silane 31a led via 32a to spirosilabiindane 33a in $75 \%$ yield and $40 \%$ ee using $[\mathrm{Rh}(\operatorname{cod}) \mathrm{Cl}]_{2}$ and $(R)-\mathrm{H}_{8}-\mathrm{BINAP}$. To achieve high levels of reactivity, the application of hydrogen acceptors was necessary. Addition of 3,3dimethyl-1-butene enabled significantly reduced reaction temperature and increased conversion and yield. Furthermore, silicon could be replaced by germanium to obtain chiral spirogermabiindane 33b. Among a variety of chiral phosphine ligands, $(R)-(S)$-BPPFA performed best giving the product 33b with moderate yield (68\%) and low ee (5\%). In this case, the addition of a hydrogen acceptor did not result in improved yields.

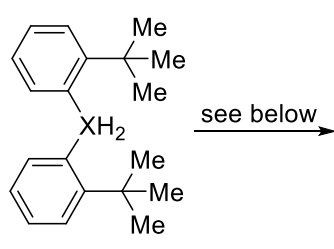

31

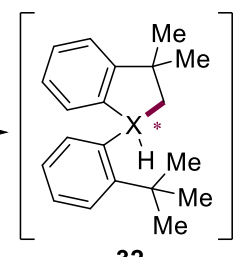

32

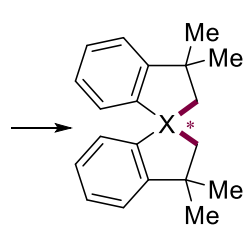

33

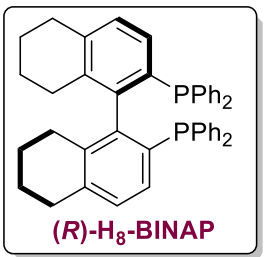

(R)- $\mathrm{H}_{8}$-BINAP

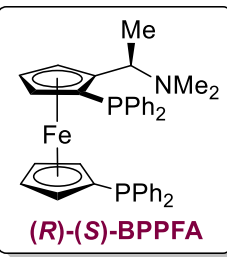

(R)-(S)-BPPFA

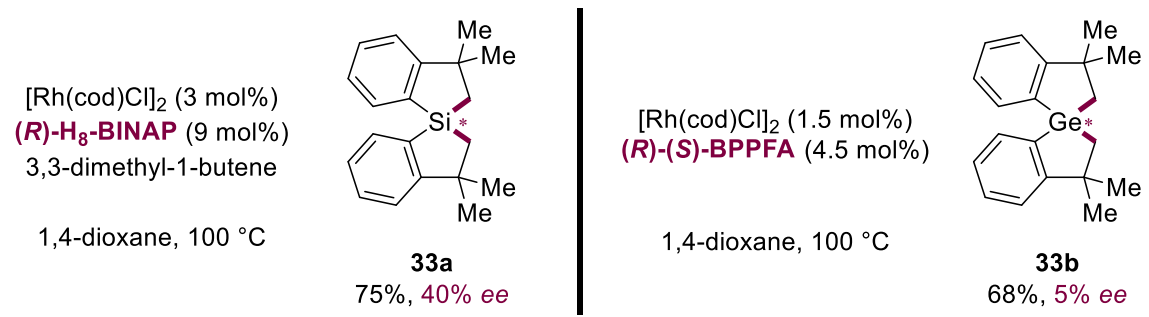

\section{Scheme 7. Rh-Catalyzed Sequential C(sp $\left.{ }^{3}\right)-H$ Bond Activation.}

In 2017, He and co-workers reported a Rh-catalyzed tandem silacyclobutane (SCB) desymmetrization/C-H silylation and intermolecular dehydrogenative silylation to form dibenzosiloles (Scheme 8) ${ }^{29} \mathrm{SCB}$ activation has been extensively studied previously in a variety of transition metal catalyzed transformations. ${ }^{30}$ In an enantiodetermining $\mathrm{Si}-\mathrm{C}$ bond activation SCBs 34 are converted via intermediate silane $\mathbf{3 5}$ to form products $\mathbf{3 6}$ bearing a quaternary silicon stereocenter. This work represents a rare example where $\mathrm{C}-\mathrm{H}$ activation is not the enantiodetermining step to achieve formation of a heteroatom stereocenter. The application of $[\mathrm{Rh}(\operatorname{cod}) \mathrm{OH}]$ and $(R)$-TMS-Segphos enabled the formation of dibenzosiloles $\mathbf{3 6}$ in good yield and high enantioselectivity. Both 2-chloro- and 3-chlorothiophene were compatible arene partners, 
delivering 36a and 36b respectively in high enantioselectivity. Unsubstituted benzene was also converted albeit in moderate yield and selectivity (36c). Meta-substituted biaryl silanes were suitable substrates delivering $\mathbf{3 6 d}$ with $88 \%$ ee. Although the isolation of intermediate $\mathbf{3 5}$ failed, a series of control experiments suggested that the SCB opening/C-H silylation occurs first with subsequent intermolecular dehydrogenative silylation to form 36. The formation of intermediate 35 is stereoselective and the subsequent dehydrogenative coupling is stereospecific and independent of the ligand chirality.

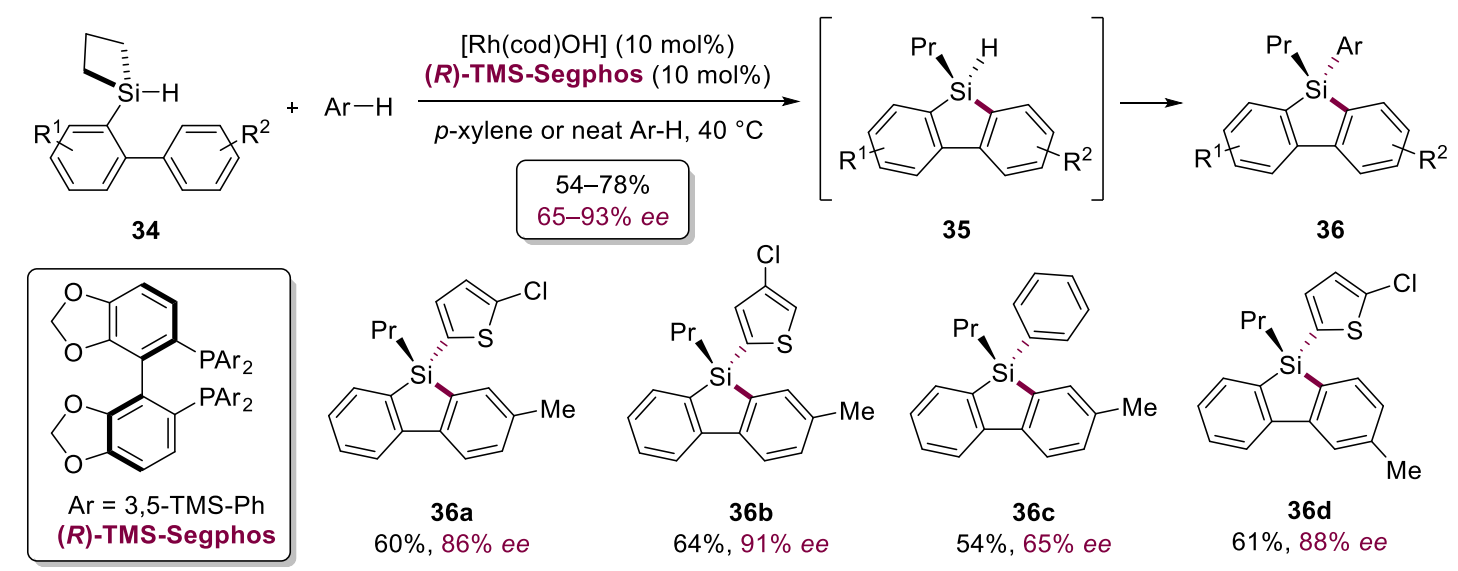

Scheme 8. Tandem Desymmetrization of Silacyclobutanes/Intermolecular Dehydrogenative Silylation.

\section{FORMATION OF PHOSPHORUS STEREOCENTERS}

Organophosphorus compounds bearing a stereocenter at phosphorus are found in bioactive molecules and materials,${ }^{31}$ but the main role of chiral phosphorus compounds is in the application as robust and versatile ligand scaffolds, or as organocatalysts in asymmetric catalysis. ${ }^{32}$ Typically, chiral $\mathrm{P}(\mathrm{III})$-compounds are used as ligands in transition-metal catalysis, ${ }^{7}$ and $\mathrm{P}(\mathrm{V})$-compounds serve as Lewis base ${ }^{33}$ and Brønsted acid catalysts. ${ }^{34}$ While in many cases different types of chirality are placed within the backbone of the ligand, the introduction of a stereogenic center on phosphorus can be advantageous because of its closer proximity to the catalytic center. ${ }^{35}$ The comparably low number of $P$-chiral ligands is associated with the challenges in their synthesis, often relying on a variety of resolution techniques. ${ }^{36}$ Catalytic asymmetric methods exist but are still limited in scope and efficiency. ${ }^{37}$ Recently the application of $\mathrm{C}-\mathrm{H}$ functionalization technology for the synthesis of organophosphorus compounds has led to a variety of new $P$-stereogenic compounds, which were previously inaccessible. 
In 2015, the Han group presented a $\mathrm{Pd}$ (II)-catalyzed desymmetrization $\mathrm{C}-\mathrm{H}$ arylation strategy to access $P$-chiral phosphinamides (Scheme 9). ${ }^{38}$ The work is builds on the racemic transformation, previously reported by the same group. ${ }^{39}$ According to the proposed mechanism, the phosphinamide of $\mathbf{3 7}$ serves as directing group guiding the ortho $\mathrm{C}-\mathrm{H}$ metalation. Additionally the authors observed an important role of DMF, facilitating the $\mathrm{C}-\mathrm{H}$ activation event. Hypothesizing that stereoinduction is feasible if a strongly coordinating DMF-like chiral ligand is applied, a variety of amino acid derivatives were explored. ${ }^{25}$ The use of $\mathrm{Pd}(\mathrm{OAc})_{2}$ and $\mathbf{L 3}$ enabled the formation of $P$-stereogenic phosphinamides 39 in good yield and high enantioselectivity. $\mathrm{Ag}_{2} \mathrm{CO}_{3}$ serves as the oxidant while 1,4-benzoquinone (BQ) was proposed to assist reductive elimination. ${ }^{39}$ The addition of 40 equivalents of water in anhydrous DMF was crucial to improve both yield and enantioselectivity. Further studies revealed a positive influence of polar protic additives on the enantioselectivity. ${ }^{40}$ This observation was rationalized by stabilization of a transition-state through an H-bonding network provided by the additive. Meta-substituted diaryl phosphinamides 37a-c reacted smoothly and both electron-donating and electron-withdrawing groups were tolerated (39b and 39c). Furthermore, boronic esters decorated with halogen and ester functionalities (39a and 39b) were suitable substrates for this transformation delivering the products in good yield and high ee.

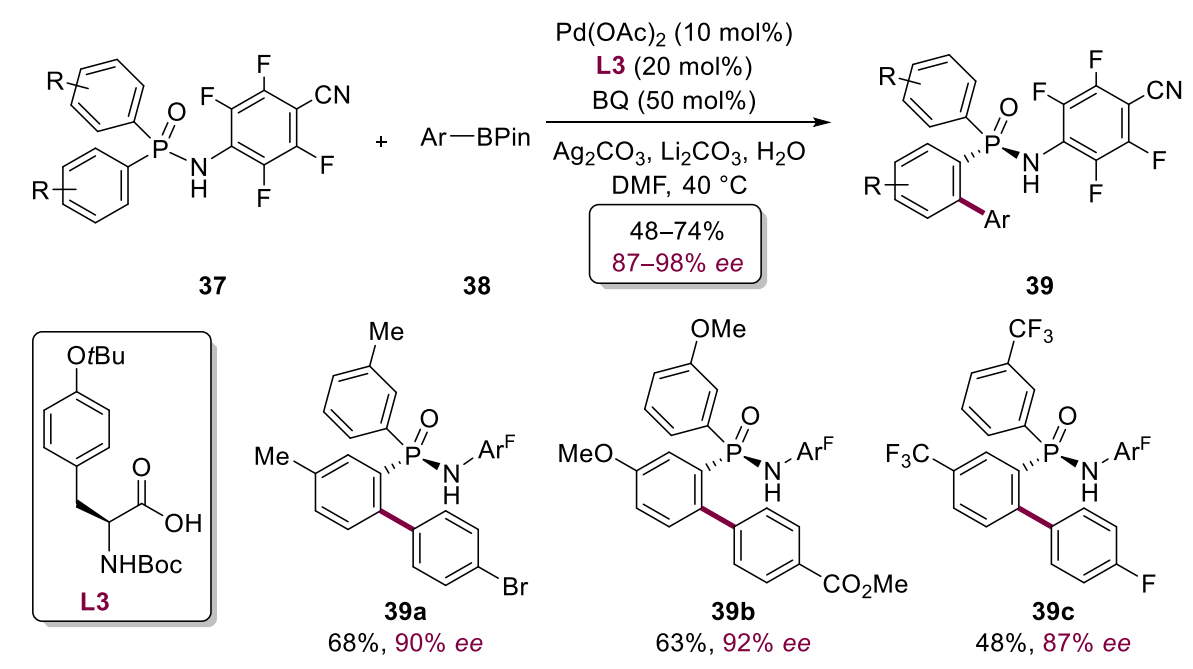

Scheme 9. Desymmetrizing C-H Arylation for the Synthesis of Phosphinamides.

By applying an intramolecular $\mathrm{Pd}(0) / \mathrm{Pd}(\mathrm{II}) \mathrm{C}-\mathrm{H}$ arylation strategy Duan and co-workers achieved, in 2015, the enantioselective formation of $P$-chiral phosphinic amides (Scheme 10).$^{41}$ Cyclization was accomplished by using $N$-(o-bromoaryl)-diarylphosphinic amides 40 and $\operatorname{Pd}(\mathrm{OAc})_{2}$ in 
combination with TADDOL-derived phosphoramidite L4. ${ }^{42}$ Substrates substituted with both electron-donating and electron-withdrawing groups were well tolerated delivering the products in high yield and high enantioselectivity (41a and 41b). Furthermore, phosphinic amide containing a cleavable $N$-PMB protecting group reacted smoothly and the corresponding product 41c was obtained in $81 \%$ yield and $91 \%$ ee. Additionally the obtained products could be converted into $P$ chiral biphenyl monophosphine ligands via the addition of organolithium compounds and $\mathrm{P}-\mathrm{N}$ bond cleavage. Shortly after this report Liu, Ma and their co-workers reported the same transformation, also applying $\mathrm{Pd}(\mathrm{OAc})_{2}$ in combination with a similar TADDOL-derived phosphoramidite L5 obtaining the $P$-chiral products in very high yields (up to 99\%) and enantioselectivity (up to $97 \%$ ee). ${ }^{43}$
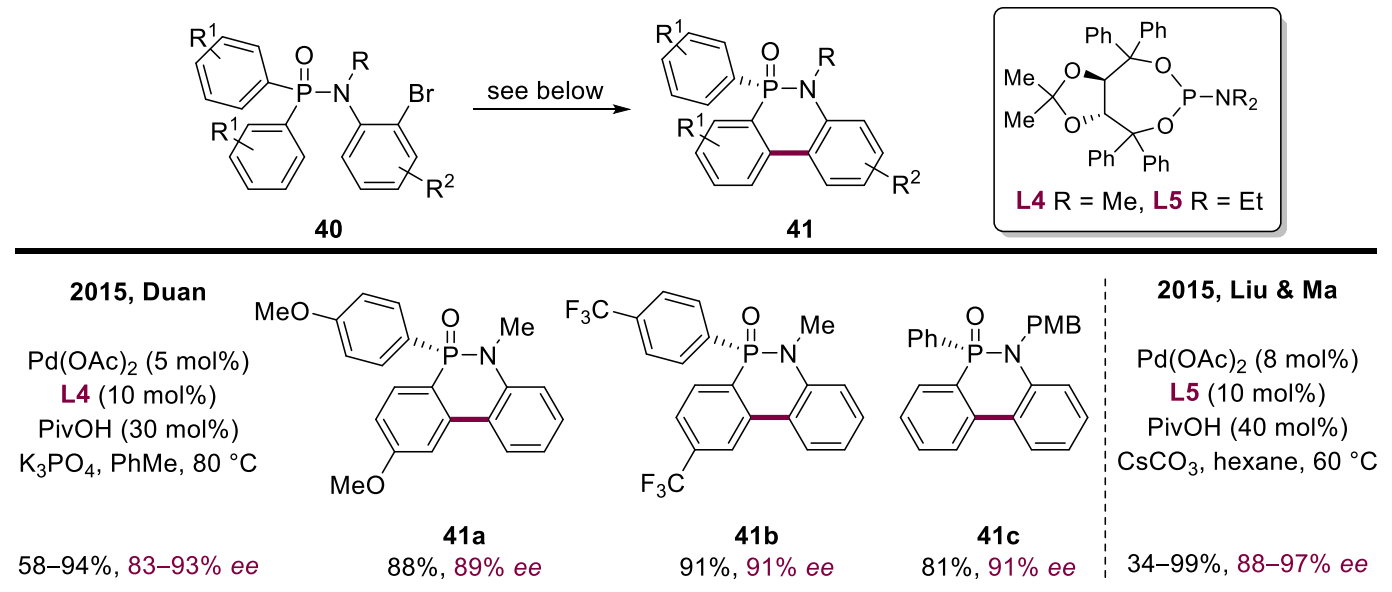

\section{Scheme 10. Pd-Catalyzed Enantioselective C-H Arylation of Phosphinic Amides.}

After these two reports the Tang group reported a similar $\mathrm{Pd}(0) / \mathrm{Pd}(\mathrm{II}) \mathrm{C}-\mathrm{H}$ arylation strategy for the formation $P$-chiral biaryl phosphonates (Scheme 11). ${ }^{44}$ Various $o$-bromoaryl phosphonates 42 were cyclized to form 43 using $\operatorname{Pd}(\mathrm{OAc})_{2}$ and a new modification of the $P$-chiral monophosphorus ligand BI-DIME L6. ${ }^{45}$ The enantioselectivity of the reaction was further improved by fine-tuning the base and $\mathrm{Ph}_{2} \mathrm{CHCOOK}$ proved optimal. Both electron-poor and electron-rich phosphonates were converted to the products (43a and 43b) in good yield and enantioselectivity. In addition, condensed arenes were well tolerated, delivering the product in good yield and enantioselectivity (43c). Product 43d was converted to $P$-chiral phosphine oxide 44 by twofold sequential alkyllithium addition. The aryloxy substituent displacement on the phosphonate occurred stereospecifically, and by reversing the order of addition of the alkyllithium reagent the opposite enantiomer of the phosphine oxide 44 could be obtained. 


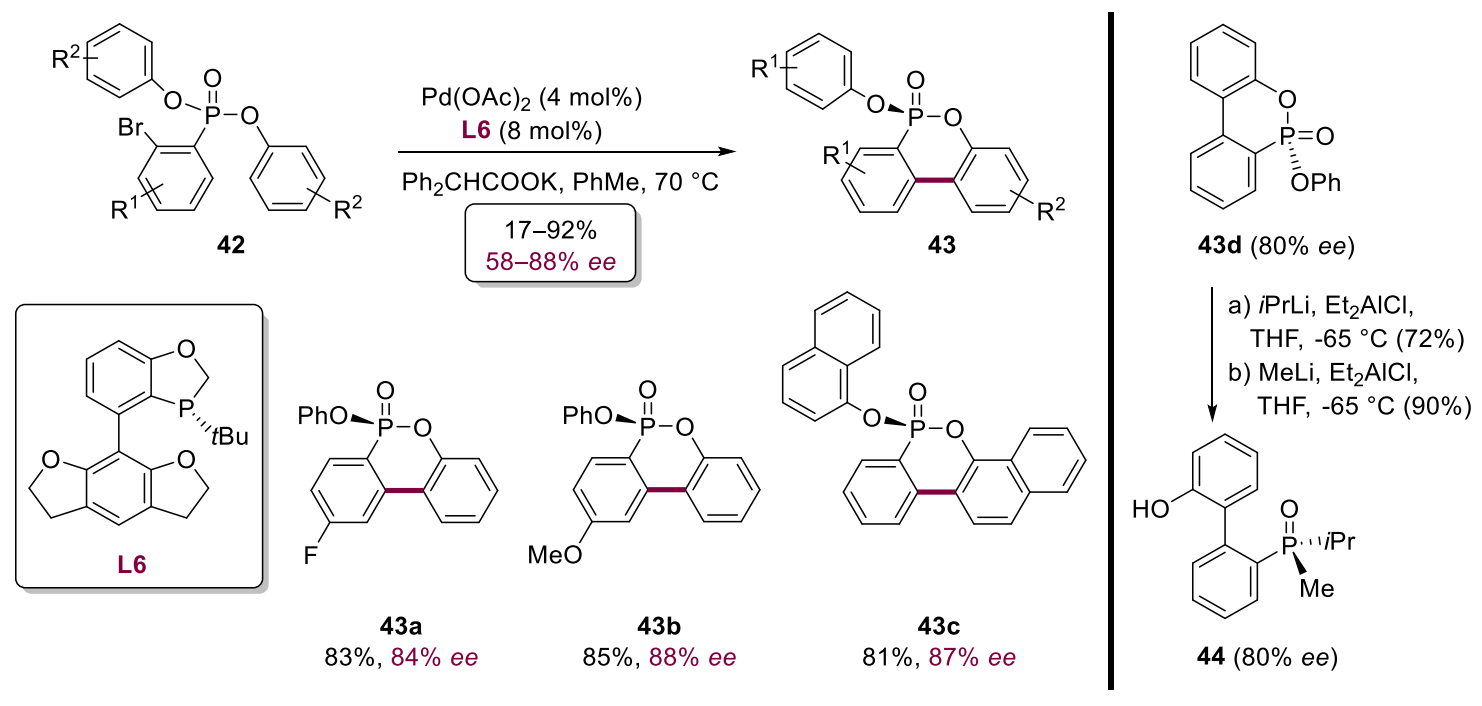

Scheme 11. Biaryl Phosphonates Synthesis by Intramolecular Pd-Catalyzed C-H Arylation.

In a related work $\mathrm{Cui}, \mathrm{Xu}$ and their coworkers disclosed an enantioselective synthesis of phosphole oxides (Scheme 12). ${ }^{46} \mathrm{~A}$ combination of $\mathrm{Pd}(\mathrm{OAc})_{2}$ and $(S, S)$-Me-Duphos enabled $\mathrm{Pd}(0) / \mathrm{Pd}(\mathrm{II}) \mathrm{C}-$ $\mathrm{H}$ arylation of different $o$-bromoaryl phosphine oxides 45 . The cyclized products 46 were obtained in moderate yield and enantioselectivity. Superior results on the same transformation were reported recently by the Duan group. ${ }^{47}$ Two catalytic systems were developed and applied for the formation of both enantiomers of the corresponding dibenzophosphole oxides 46. A Pd-catalyst containing an achiral phosphine ligand $\left(\mathrm{Pd}\left(\mathrm{PCy}_{3}\right)_{2}\right)$ and a chiral BINOL-phosphoric acid/amide mixture (L7/ $\mathbf{L 8}=1 / 1)$ proved optimal to achieve good enantioselectivity. Dibenzophosphole oxide $(S)$-46a was obtained in $95 \%$ yield and $88 \%$ ee. Furthermore, a nonlinear effect was observed for this catalyst system and the involvement of more than one phosphoric acid/amide in the enantioselective $\mathrm{C}-\mathrm{H}$ palladation step was suggested. The second set of conditions relied on the use of $\operatorname{Pd}(\mathrm{OAc})_{2}$ and $(R)$-Segphos in combination with pivalic acid. Dibenzophosphole oxide $(R)$-46a was obtained in moderate yield and high enantioselectivity under these conditions. 


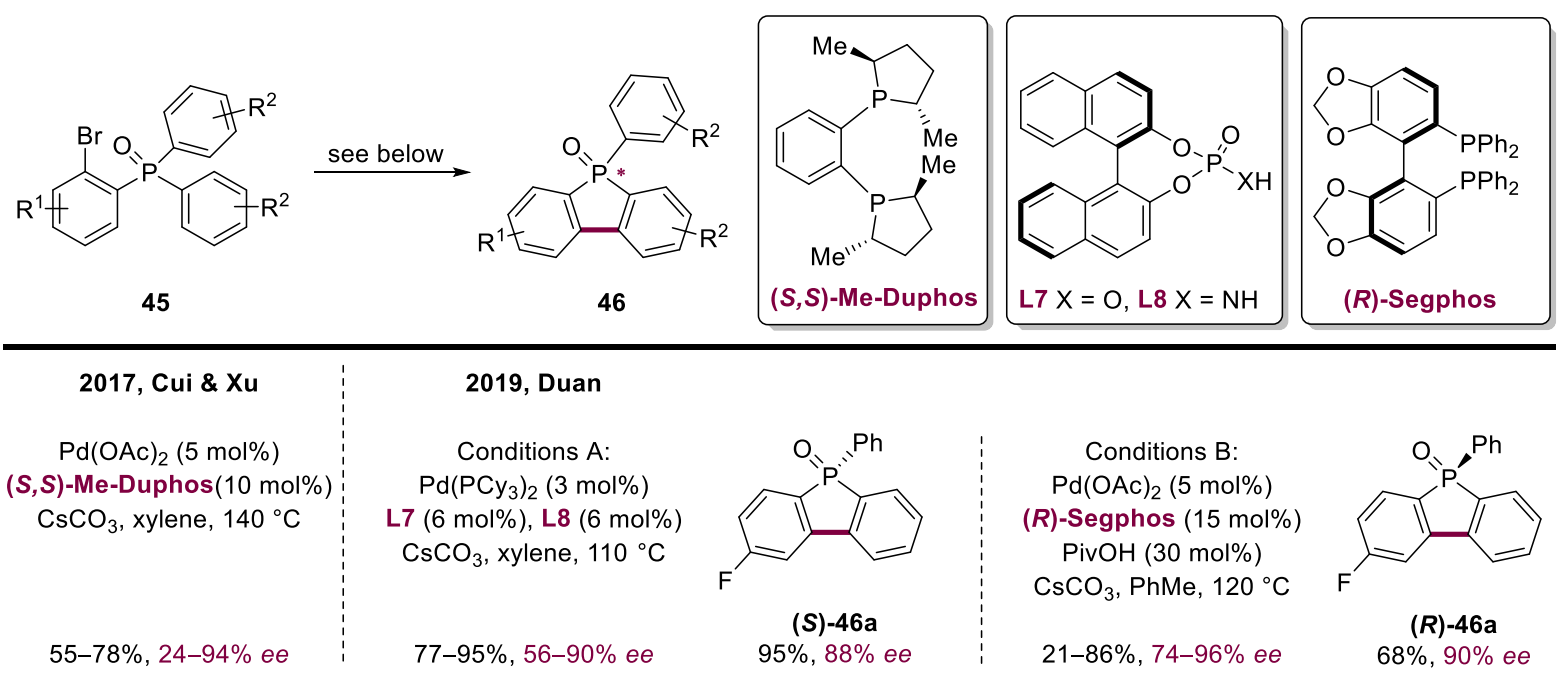

\section{Scheme 12. Pd-Catalyzed Enantioselective Synthesis of Dibenzophosphole oxides.}

In 2015, the Chang group demonstrated a dual role of a carboxylic acid additive in an Ir-catalyzed enantioselective $\mathrm{C}-\mathrm{H}$ amidation of diaryl phosphine oxides 47 (Scheme 13). ${ }^{48}$ The methodology drew upon their earlier report on the development of a diastereoselective auxiliary controlled transformation. ${ }^{49}$ The combination of $\left[\mathrm{Cp}^{*} \mathrm{IrCl}_{2}\right]_{2}$ and $\mathrm{AgNTf}_{2}$ to generate a dicationic iridium complex, and the tartaic acid derivative L9 as chiral ligand gave the $\mathrm{C}-\mathrm{H}$ amidated phosphine oxides 48 in good yields and low enantioselectivity using tosyl azide as the amidation reagent. Mechanistic studies suggested that the chiral acid takes part in the rate-limiting and enantiodetermining concerted metalation deprotonation (CMD) step. ${ }^{48,50}$ Subsequently Cramer and coworkers showcased that high levels of enantiocontrol are feasible using a combination of readily modifiable $\mathrm{Cp}^{\mathrm{x}} \mathrm{Ir}(\mathrm{III})$ complexes $^{51}$ and a chiral carboxylic acid. Applying Cat-1 together with tert-leucine derived $(S)$-L10 gave the products 48 in high yield and very high enantioselectivity. ${ }^{52}$ An extensive investigation of chiral carboxylic acids revealed a strong cooperative effect between the $\mathrm{Cp}^{\mathrm{x}}$ ligand and phthaloyl tert-leucine $(S)$-L10 delivering phosphine oxide 48a in $83 \%$ yield and $92 \%$ ee. Application of the opposite enantiomer $(R)$-L10 resulted in significantly lower reactivity and erosion of enantioselectivity (15\% yield and $20 \%$ ee for $\mathbf{4 8 a}$ ) highlighting the strong matched-mismatched effect between the $\mathrm{Cp}^{\mathrm{x}}$ ligand and the chiral acid. Phosphine oxides bearing a tert-butyl substituent were converted to the $\mathrm{C}-\mathrm{H}$ amidated products in excellent enantioselectivity $(\mathbf{4 8 b}$ and $\mathbf{4 8 c})$. The readily cleavable $o$-nosyl group could be introduced easily delivering product $48 \mathrm{c}$ in $92 \%$ yield and $96 \%$ ee. 

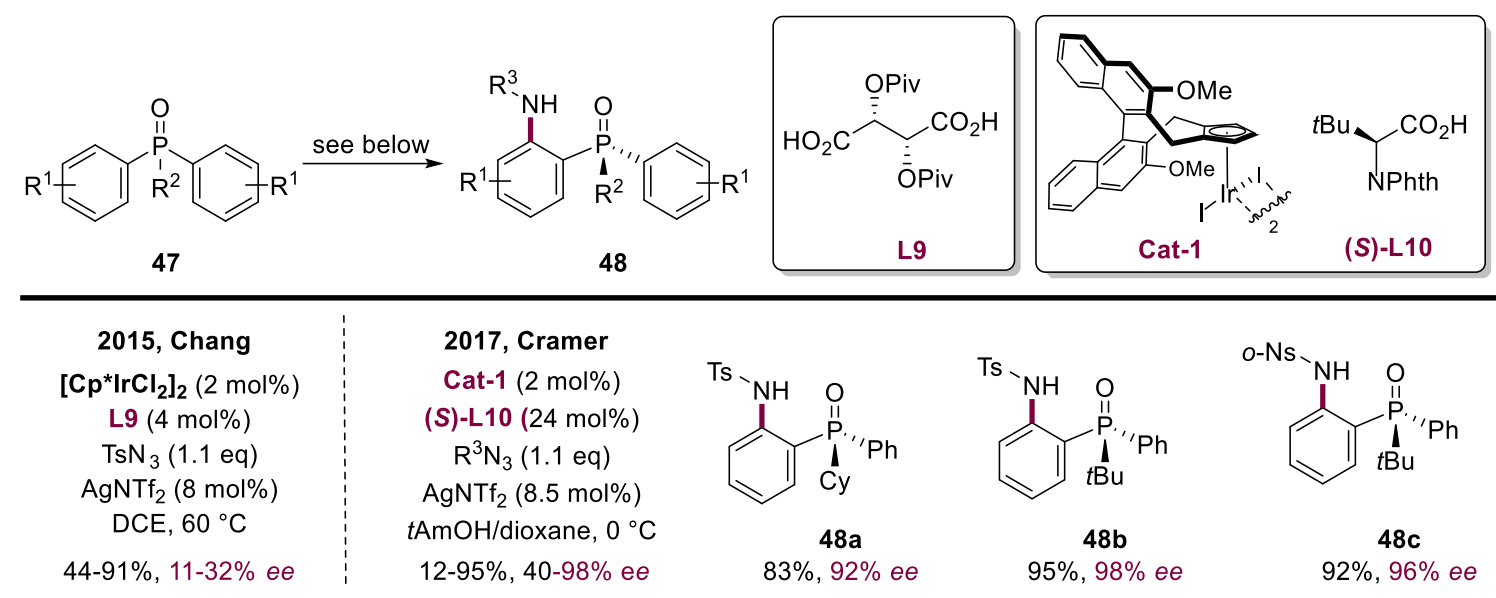

Scheme 13. Enantioselective Ir-Catalyzed C-H Amidation of Phosphine Oxides.

In 2018, the Cramer group employed the $\mathrm{C} \mathrm{p}^{\mathrm{x}} \operatorname{Ir}(\mathrm{III}) /$ chiral carboxylic acid system to achieve $\mathrm{C}-\mathrm{H}$ arylation of phosphine oxides 49, providing access to $P$ - and axially chiral products 51 (Scheme 14). ${ }^{53}$ The use of quinone diazides $\mathbf{5 0}$ in an Ir-catalyzed racemic arylation was reported previously by Yang and co-workers. ${ }^{54}$ Application of the powerful combination of $\mathrm{Cp}{ }^{\mathrm{x}} \operatorname{Ir}(\mathrm{III})$ Cat-1 and $(S)$ L10 enabled the formation of $P$-chiral biaryl phosphine oxides in excellent yield and enantioselectivity (51a and 51b). Introduction of ortho-substituted diazides generated a stable chiral axis, delivering products with both axial and $P$-chirality in excellent diastereo- and enantioselectivity (51c and 51d). The protocol was also applicable for the enantioselective synthesis of purely axial chiral phosphine oxides (51e and 51f), underlining that the chiral $\mathrm{Cp}^{\mathrm{x}}$ ligand also has a bearing on the formation of the atropchiral biaryl axis. The obtained products could be reduced to the corresponding phosphines and hence serve as access to chiral monodentate MOP-type ligands. ${ }^{55}$ 


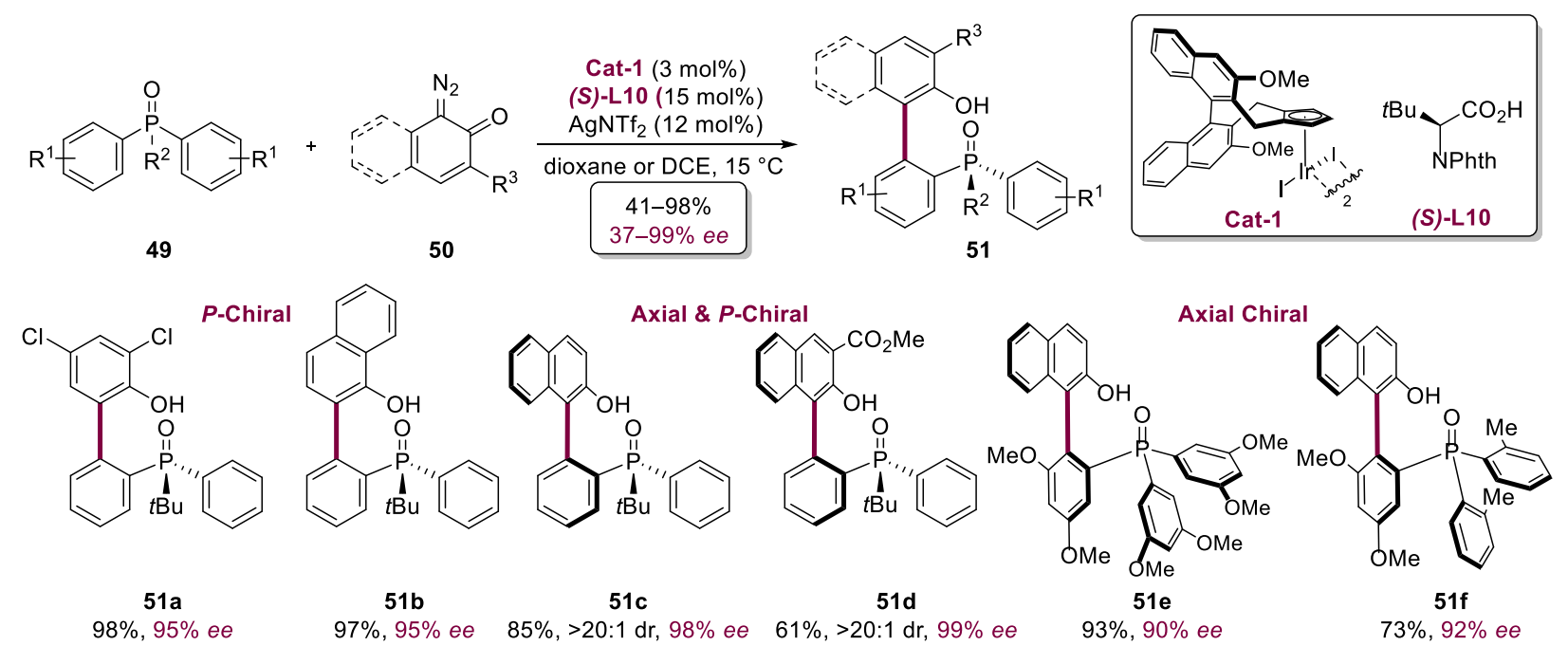

Scheme 14. C-H Arylation to Access $P$ - and Axially Chiral Biaryl Phosphine Oxides.

In 2017, Sun and Cramer reported a desymmetrization of phosphinamides $\mathbf{5 2}$ generating $P$-chiral cyclic products 54 (Scheme 15). ${ }^{56}$ The first example of a Rh(III)-catalyzed enantiodetermining C$\mathrm{H}$ activation, and subsequent trapping with internal alkynes 53 enabled the formation of the annulated products 54 in high enantioselectivity. ${ }^{57}$ Reducing the reversibility of the $\mathrm{C}-\mathrm{H}$ activation was crucial to obtain high ee. This was achieved by adding the inorganic base $\mathrm{K}_{2} \mathrm{CO}_{3}$, which efficiently mitigated the reversibility of the enantiodetermining step. By applying atropchiral Cat2 and $\mathrm{Ag}_{2} \mathrm{CO}_{3}$ as the stoichiometric oxidant, a variety of differently substituted diaryl phosphinamides were converted in good yield and high enantioselectivity. ${ }^{58}$ The alkyne acceptors could be readily exchanged. Diaryl (e.g., 54a) and unsymmetrical substituted alkynes (e.g., 54b and 54c) were capable substrates delivering the products with high ee. Additionally, the regioselectivity for unsymmetrical alkynes was $>20: 1$ in all cases, outperforming the achiral $\mathrm{Cp} * \mathrm{Rh}(\mathrm{III})$ catalyst, for which poor to modest regioselectivity was observed. Dialkyl alkynes were converted in high enantioselectivity as well, albeit with lower yield (e.g., 54d). Furthermore, highly enantiospecific reduction of the $\mathrm{P}(\mathrm{V})$-products $\mathbf{5 4}$ to valuable $\mathrm{P}(\mathrm{III})$-chiral compounds was achieved under carefully optimized conditions. 

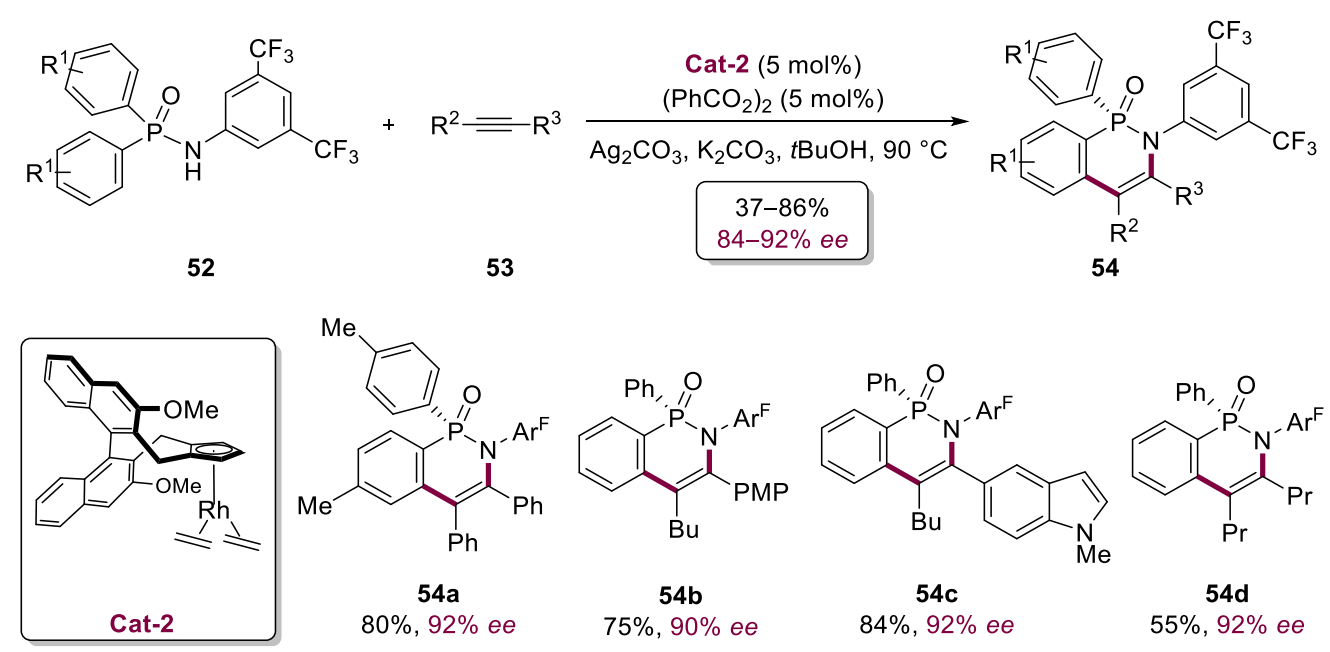

\section{Scheme 15. Rh-Catalyzed Enantiotopic C-H Activation of Phosphinamides.}

Sun and Cramer further extended this methodology to alkyl, aryl phosphinic amides to obtain enantioenriched products through a kinetic resolution process (Scheme 16). ${ }^{59}$ Chiral phosphinic amides 55 were selectively converted into $\mathbf{5 7}$ due to a difference in cyclometalation rates (see Scheme 2a). Crucial for a sufficient rate difference of the two starting material enantiomers was the development of new trisubstituted $\mathrm{Cp}^{\mathrm{x}}$ ligands (Cat-3) ${ }^{60}$ The application of Cat-3 enabled the resolution of phosphinic amides 55, delivering highly enantioenriched starting material $(S)$ - 55 and cyclized products 57 with $s$-values ${ }^{61}$ up to 50 . Different aryl substituents had little influence on the reaction performance delivering the products in high enantioselectivity (e.g., 55a and 57a). Longer alkyl chains decorated with a benzyl ether group (e.g., 55b and 57b) and unsymmetrically substituted alkynes (e.g., 55c and 57c) were suitable reaction partners delivering the products with high selectivity. Furthermore, product 57a was successfully applied as Lewis-base catalyst in an enantioselective reductive aldol reaction. 


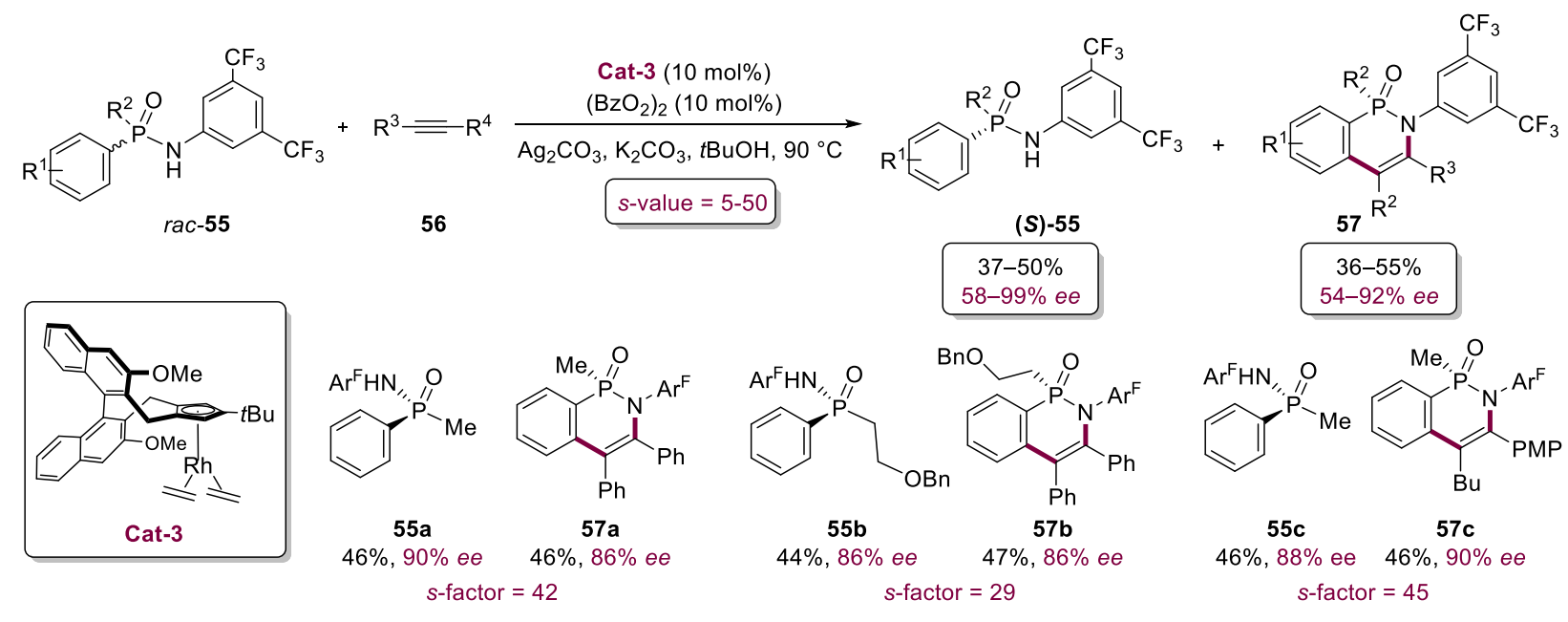

Scheme 16. Rh-Catalyzed Kinetic Resolution of Phosphinic Amides.

\section{FORMATION OF SULFUR STEREOCENTERS}

Biomolecules containing sulfur stereocenters are ubiquitous in nature and play an important role in the chemical reactions of general metabolism. ${ }^{8}$ In particular, chiral sulfonium ions, sulfoxides (both oxidation state IV) and sulfoximines (oxidation state VI) bind stereoselectively with enzymes in metabolic processes. Because of the significant bioactivity, an increasing number of marketed drugs and bioactive compounds entering clinical trials contain sulfoxides and sulfoximines in enantiopure form. ${ }^{9}, 62$ Furthermore, chiral sulfoximines can improve pharmacokinetic properties, compared to commonly introduced sulfone and sulfonamide derivatives. ${ }^{63}$ In addition, chiral sulfoxides are of high importance in stereoselective synthesis. Sulfoxides serve as efficient and versatile chiral auxiliaries for the formation of $\mathrm{C}-\mathrm{C}$ and $\mathrm{C}-\mathrm{X}$ bonds, ${ }^{64}$ or as chiral ligands in asymmetric catalysis. ${ }^{65}$ Traditional methods to access enantiopure organosulfur compounds include diastereoselective transformations, various resolution techniques and biocatalytic reactions. ${ }^{64,66}$ Methods to access compounds containing a sulfur stereocenter in a catalytic asymmetric fashion are still limited in scope and efficiency. ${ }^{64,}{ }^{67}$ Recently $\mathrm{C}-\mathrm{H}$ activation technology has been applied to efficiently access chiral sulfoxides and sulfoximines.

In 2018, Wang and co-workers introduced a Pd(II)-catalyzed enantioselective $\mathrm{C}-\mathrm{H}$ olefination of diaryl sulfoxides (Scheme 17). ${ }^{68}$ A survey of a range of different mono-protected amino acids ${ }^{25}$ revealed Ac-Leu-OH as optimal ligand for this transformation. Desymmetrization of prochiral diaryl sulfoxides 58 gave the alkenylated products $(60 a-60 c)$ in moderate yield and high enantioselectivity. Both ortho-substituted and electron-poor sulfoxides were converted with 
excellent enantioselectivity (60a and 60b). Aside from methyl acrylate, diethyl vinyl phosphonate was also a competent reaction partner delivering the product $60 \mathbf{c}$ with good ee. The yields were reflective of moderate conversion rates. Most likely due to strong coordination of the sulfoxides to palladium resulting in possible deactivation of the catalyst. The remaining starting materials were recovered without significant loss. Additionally, non-symmetric diaryl sulfoxides $\mathbf{5 8}$ were converted in a parallel kinetic resolution (see Scheme $2 b$ ) to deliver two products from the racemic starting materials. Diaryl sulfoxides with two different ortho substituents reacted to give products 60d and 60e in excellent enantioselectivity. Mechanistic studies confirmed that a regiodivergent parallel kinetic resolution was operative.

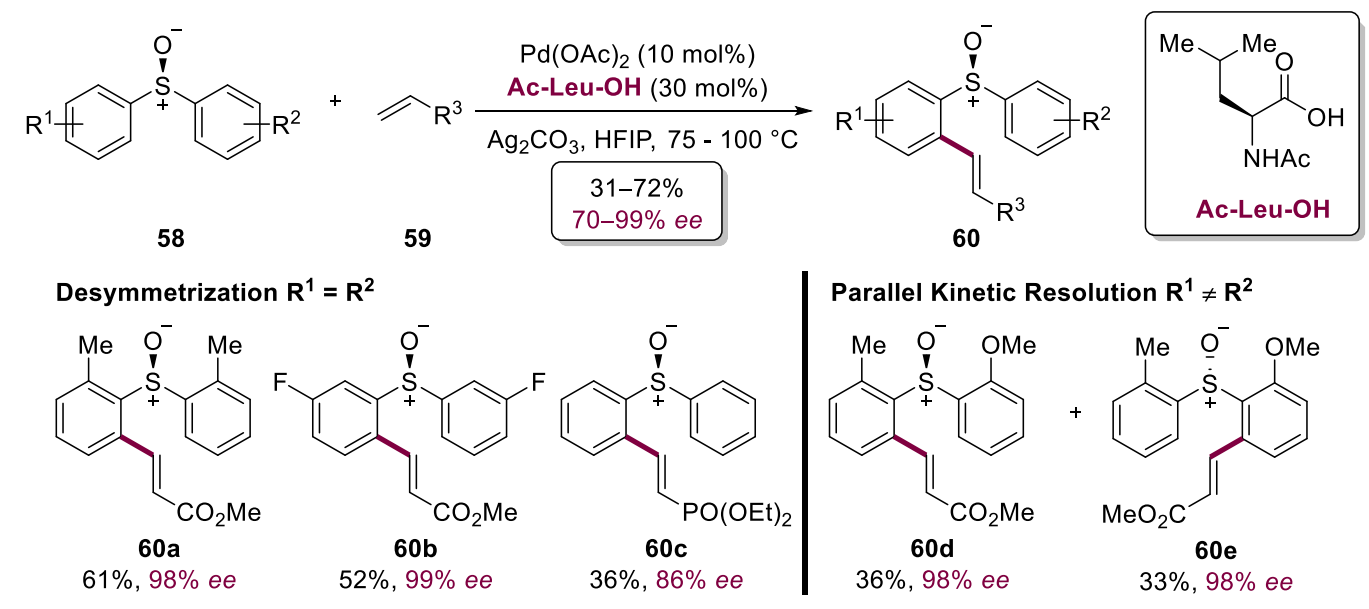

Scheme 17. Pd-Catalyzed Enantioselective C-H Functionalization of Diaryl Sulfoxides.

In 2018, the desymmetrization of sulfoximines under $\mathrm{Rh}(\mathrm{III})$-catalyzed $\mathrm{C}-\mathrm{H}$ Functionalization was reported independently by the Cramer group and by the Li group (Scheme 18). ${ }^{69}$ Symmetric diaryl sulfoximines 61 were converted applying diazo compounds 62 to form chiral-at-sulfur 1,2benzothiazines 63 using different modifications of $\mathrm{Cp}^{\mathrm{x}} \mathrm{Rh}(\mathrm{III})$ catalysts. Sun and Cramer applied their trisubstituted $\mathrm{Cp}^{\mathrm{x}}$ ligand (Cat-4) in combination with tert-leucine-derived ligand $\mathbf{L 1 1}$ to obtain the annulated products in high yield and enantioselectivity (e.g., 63a).${ }^{59-60}$ A variety of different diazo compounds proved to be capable reaction partners for this transformation delivering the products in high ee. However, application of less reactive diazo compounds led to decreased enantioselectivity. As the trapping of the diazo reaction partner occurs after the enantiodetermining $\mathrm{C}-\mathrm{H}$ activation, no influence on the ee was expected. Reversibility of the $\mathrm{C}-$ $\mathrm{H}$ activation step was suggested to explain the observed inferior results for less reactive diazo compounds. Li and co-workers applied another $\mathrm{Cp}{ }^{x} \mathrm{Rh}(\mathrm{III})$ catalyst Cat-5 in combination with 
differently substituted benzoic acid derivatives achieving an enantiodivergent desymmetrization of sulfoximines 61. The use of Cat-5 and 2-methoxybenzoic acid gave benzothiazine $(R)-63 \mathbf{a}$ in very high yield and enantioselectivity. Interestingly, when applying 2,6-dimethoxybenzoic acid the opposite product enantiomer (S)-63a was obtained in moderate selectivity, which could be further improved to $86 \%$ ee by changing the solvent to tetrachloroethane. Additionally, the coupling of sulfoximines with $\alpha$-diazo malonates was achieved using modified reaction conditions.

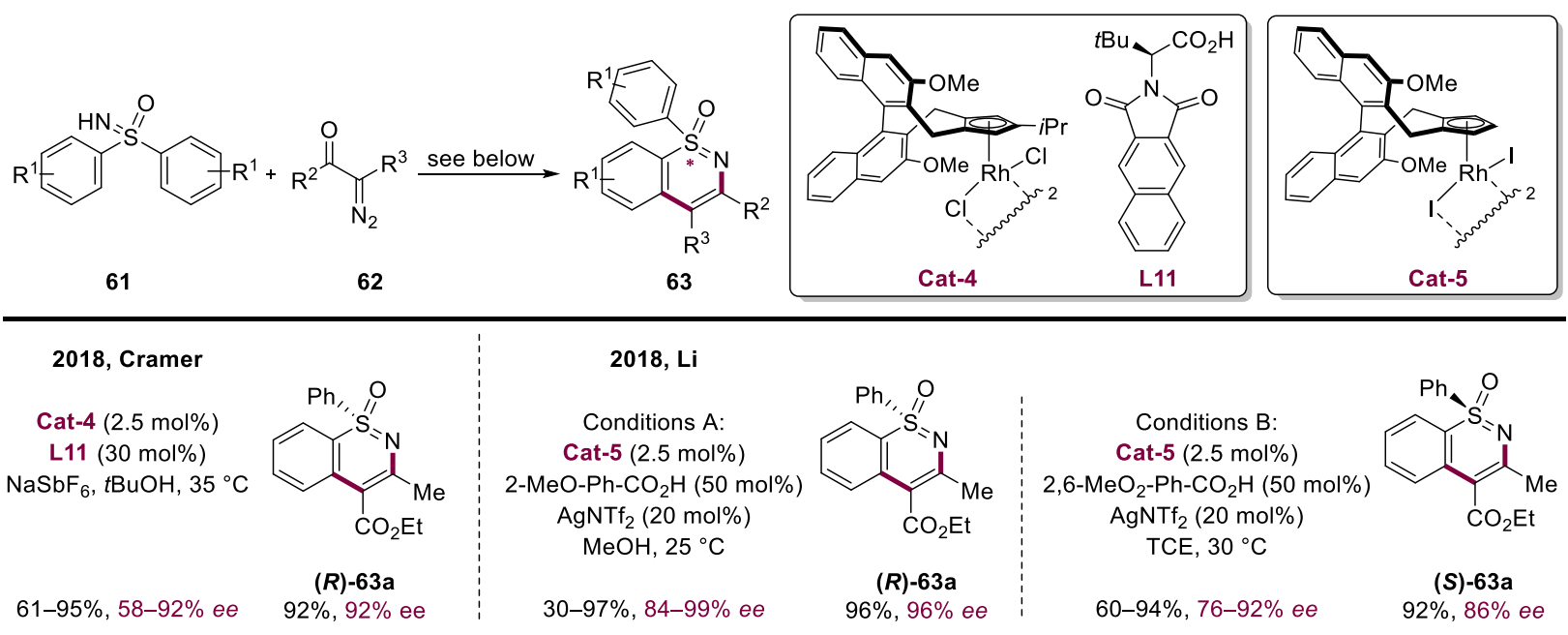

\section{Scheme 18. Rh-Catalyzed Enantioselective C-H Functionalization of Sulfoximines.}

Further extending this methodology, Brauns and Cramer recently presented the kinetic resolution of chiral sulfoximines (Scheme 19) ${ }^{70}$ Addressing the limitations of two identical aryl substituents, the kinetic resolution (see Scheme 2a) allowed for the conversion of racemic aryl alkyl substituted sulfoximines 64 to cyclic benzothiazines 66 and additionally provided with enantioenriched acyclic starting materials (S)-64. Screening of different trisubstituted $\mathrm{Cp}^{\mathrm{x}} \mathrm{Rh}(\mathrm{III})$ catalysts and carboxylic acids revealed Cat-6 in combination with phenylalanine-derived acid L12 as optimal, delivering the products 66 in excellent selectivity. A variety of different aryl and alkyl substituted sulfoximines 64 were tolerated and $p$-nitroaryl methyl sulfoximine 64a was resolved with excellent $s$-value ${ }^{61}$ and very high enantioselectivity for both the acyclic starting material $(S)$-64a and the annulated sulfoximine 66a. Additionally 64a was successfully converted to a known precursor of a proline-rich tyrosine kinase 2 (PYK2) inhibitor, currently undergoing clinical trials. ${ }^{9 b}$ 


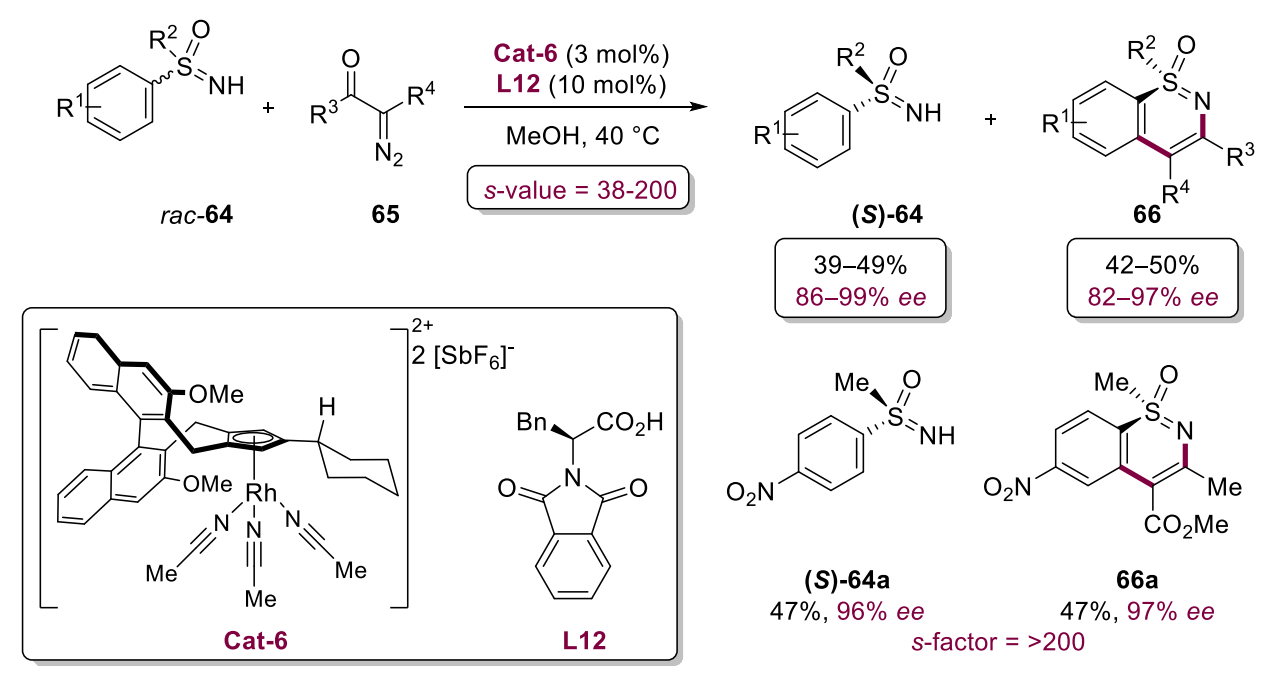

Scheme 19. Kinetic Resolution of Sulfoximines via Rh-Catalyzed C-H Functionalization.

\section{CONCLUSIONS AND FUTURE PERSPECTIVES}

The application of enantioselective $\mathrm{C}-\mathrm{H}$ functionalization strategies has provided efficient access to valuable chiral heteroatom scaffolds over the past seven years. The reported structures include bioactive molecules currently in clinical trials and chiral ligand scaffolds, which could be applied in asymmetric catalysis. The majority of the methodologies were published from 2015 onwards and the formation of sulfur stereogenic centers via enantioselective $\mathrm{C}-\mathrm{H}$ functionalization was initiated only in 2018, highlighting the room for further developments.

Approaches so far relied mainly on the desymmetrizing $\mathrm{C}\left(\mathrm{sp}^{2}\right)-\mathrm{H}$ activation of prochiral substrates with formation of a heteroatom stereocenter in a distal position. Enantioselective $\mathrm{C}\left(\mathrm{sp}^{3}\right)-\mathrm{H}$ activation is developing rapidly over the last years, enabling functionalization in closer proximity to the formed stereocenter. ${ }^{2 b}$ Application of these recent activation strategies to the formation of heteroatom stereocenters would enable access to more diverse, previously inaccessible product scaffolds. Another area of active research within enantioselective $\mathrm{C}-\mathrm{H}$ functionalization is the application of $3 \mathrm{~d}$ transition-metal catalysts. ${ }^{2 \mathrm{c}, 2 \mathrm{~d}}$ The base metal complexes can serve as worthwhile alternative catalysts for established methodologies, but can also provide with complementary reactivity to the presented noble metal complexes. Hence, the introduction of $3 \mathrm{~d}$ transition-metal catalysis would also provide with a greater diversity in accessible stereogenic heteroatom molecules. Given the great importance of chiral heteroatom scaffolds, in particular in drug discovery, we expect enantioselective $\mathrm{C}-\mathrm{H}$ functionalization strategies to play an increasingly 
important role in target-oriented synthesis, to access complex structures containing chiral heteroatoms more efficiently.

\section{AUTHOR INFORMATION}

\subsection{Corresponding Author}

* E-mail: nicolai.cramer@epfl.ch

\subsection{Notes}

The authors declare no competing financial interest.

\section{ACKNOWLEDGMENT}

This work is supported by the Swiss National Science Foundation (no. 155967).

\section{REFERENCES}

1. (a) Dong, Z.; Ren, Z.; Thompson, S. J.; Xu, Y.; Dong, G. Transition-Metal-Catalyzed CH Alkylation Using Alkenes Chem. Rev. 2017, 117, 9333-9403. (b) He, J.; Wasa, M.; Chan, K. S. L.; Shao, Q.; Yu, J.-Q. Palladium-Catalyzed Transformations of Alkyl C-H Bonds Chem. Rev. 2017, 117, 8754-8786. (c) Hummel, J. R.; Boerth, J. A.; Ellman, J. A. Transition-Metal-Catalyzed C-H Bond Addition to Carbonyls, Imines, and Related Polarized $\pi-$ Bonds Chem. Rev. 2017, 117 , 9163-9227. (d) Kim, D.-S.; Park, W.-J.; Jun, C.-H. Metal-Organic Cooperative Catalysis in C-H and C-C Bond Activation Chem. Rev. 2017, 117, 8977-9015. (e) Murakami, K.; Yamada, S.; Kaneda, T.; Itami, K. C-H Functionalization of Azines Chem. Rev. 2017, 117, 9302-9332.

2. (a) Newton, C. G.; Wang, S.-G.; Oliveira, C. C.; Cramer, N. Catalytic Enantioselective Transformations Involving $\mathrm{C}-\mathrm{H}$ Bond Cleavage by Transition-Metal Complexes Chem. Rev. 2017, 117, 8908-8976. (b) Saint-Denis, T. G.; Zhu, R.-Y.; Chen, G.; Wu, Q.-F.; Yu, J.-Q. Enantioselective $\mathrm{C}\left(\mathrm{sp}^{3}\right)-\mathrm{H}$ Bond Activation by Chiral Transition Metal Catalysts Science 2018, 359, eaao4798. (c) Woźniak, Ł.; Cramer, N. Enantioselective CH Bond Functionalizations by 3d Transition-Metal Catalysts Trends in Chemistry 2019, 1, 471-484. (d) Loup, J.; Dhawa, U.; Pesciaioli, F.; Wencel-Delord, J.; Ackermann, L. Enantioselective C-H Activation with EarthAbundant 3d Transition Metals Angew. Chem. Int. Ed., DOI:10.1002/anie.201904214.

3. Kiełbasński, P.; Mikołajczyk, M. In Future Directions in Biocatalysis, Matsuda, T., Ed. Elsevier Science B.V.: Amsterdam, 2007; Vol. 2, pp 159-203.

4. (a) Chen, J.; Cao, Y. Silole-Containing Polymers: Chemistry and Optoelectronic Properties Macromol. Rapid Commun. 2007, 28, 1714-1742. (b) Oishi, M.; Kawakami, Y. Synthesis of Stereoregular and Optically Active Polysiloxanes Containing 1,3-Dimethyl-1,3diphenyldisiloxane as a Constitutional Unit Macromolecules 2000, 33, 1960-1963.

5. Prelog, V.; Wieland, P. Über die Spaltung der Tröger'schen Base in optische Antipoden, ein Beitrag zur Stereochemie des dreiwertigen Stickstoffs Helv. Chim. Acta 1944, 27, 1127-1134. 
6. Mislow, K. PYRAMIDAL INVERSION BARRIERS OF PHOSPHINES AND ARSINES*, $\dagger$ Transactions of the New York Academy of Sciences 1973, 35, 227-242.

7. Kamer, P. C. J.; Leeuwen, P. W. N. M. v., Phosphorus(III)-Ligands in Homogeneous Catalysis: Design and Synthesis. Wiley, Hoboken, 2012.

8. Bentley, R. Role of sulfur chirality in the chemical processes of biology Chem. Soc. Rev. 2005, 34, 609-624.

9. $\quad$ (a) Lindberg, P.; Brändström, A.; Wallmark, B.; Mattsson, H.; Rikner, L.; Hoffmann, K.J. Omeprazole: The first proton pump inhibitor Medicinal Research Reviews 1990, 10, 1-54. (b) Walker, D. P.; Zawistoski, M. P.; McGlynn, M. A.; Li, J.-C.; Kung, D. W.; Bonnette, P. C.; Baumann, A.; Buckbinder, L.; Houser, J. A.; Boer, J.; Mistry, A.; Han, S.; Guzman-Perez, L. X.; Angel Sulfoximine-Substituted Trifluoromethylpyrimidine Analogs as Inhibitors of Proline-Rich Tyrosine Kinase 2 (PYK2) Show Reduced hERG Activity Bioorg. Med. Chem. Lett. 2009, 19, 3253-3258.

10. (a) Crabtree, R. H. Alkane C-H Activation and Functionalization with Homogeneous Transition Metal Catalysts: a Century of Progress-a New Millennium in Prospect $J$. Chem. Soc., Dalton Trans. 2001, 2437-2450. (b) Dick, A. R.; Sanford, M. S. Transition Metal Catalyzed Oxidative Functionalization of Carbon-Hydrogen Bonds Tetrahedron 2006, 62, 2439-2463.

11. Robinson, D. E. J. E.; Bull, S. D. Kinetic Resolution Strategies Using Non-Enzymatic Catalysts Tetrahedron: Asymmetry 2003, 14, 1407-1446.

12. (a) Vedejs, E.; Chen, X. Parallel Kinetic Resolution J. Am. Chem. Soc. 1997, 119, 2584 2585. (b) Dehli, J. R.; Gotor, V. Parallel kinetic resolution of racemic mixtures: a new strategy for the preparation of enantiopure compounds? Chem. Soc. Rev. 2002, 31, 365-370.

13. Cui, Y.-M.; Lin, Y.; Xu, L.-W. Catalytic Synthesis of Chiral Organoheteroatom Compounds of Silicon, Phosphorus, and Sulfur via Asymmetric Transition Metal-Catalyzed C-H Functionalization Coord. Chem. Rev. 2017, 330, 37-52.

14. (a) Xiao, H.; Leng, B.; Tian, H. Hole Transport Triphenylamine-Spirosilabifluorene Alternating Copolymer: Synthesis and Optical, Electrochemical and Electroluminescent Properties Polymer 2005, 46, 5707-5713. (b) Hou, J.; Chen, H.-Y.; Zhang, S.; Li, G.; Yang, Y. Synthesis, Characterization, and Photovoltaic Properties of a Low Band Gap Polymer Based on Silole-Containing Polythiophenes and 2,1,3-Benzothiadiazole J. Am. Chem. Soc. 2008, 130, 16144-16145. (c) Huo, L.; Chen, H.-Y.; Hou, J.; Chen, T. L.; Yang, Y. Low Band Gap Dithieno[3,2-b:2',3'-d]silole-Containing Polymers, Synthesis, Characterization and Photovoltaic Application Chem. Commun. 2009, 5570-5572. (d) Duan, C.; Cai, W.; Huang, F.; Zhang, J.; Wang, M.; Yang, T.; Zhong, C.; Gong, X.; Cao, Y. Novel Silafluorene-Based Conjugated Polymers with Pendant Acceptor Groups for High Performance Solar Cells Macromolecules 2010, 43, 5262-5268.

15. Mills, J. S.; Showell, G. A. Exploitation of Silicon Medicinal Chemistry in Drug Discovery Expert Opin. Investig. Drugs 2004, 13, 1149-1157.

16. Barraza, S. J.; Denmark, S. E. Synthesis, Reactivity, Functionalization, and ADMET Properties of Silicon-Containing Nitrogen Heterocycles J. Am. Chem. Soc. 2018, 140, 6668-6684.

17. Xu, L.-W. In Organosilicon Compounds, Lee, V. Y., Ed. Academic Press: 2017; pp 145194.

18. (a) Shintani, R. Recent Advances in the Transition-Metal-Catalyzed Enantioselective Synthesis of Silicon-Stereogenic Organosilanes Asian J. Org. Chem. 2015, 4, 510-514. (b) Xu, L.-W.; Li, L.; Lai, G.-Q.; Jiang, J.-X. The Recent Synthesis and Application of Silicon-Stereogenic 
Silanes: A Renewed and Significant Challenge in Asymmetric Synthesis Chem. Soc. Rev. 2011, 40, 1777-1790.

19. Shintani, R.; Otomo, H.; Ota, K.; Hayashi, T. Palladium-Catalyzed Asymmetric Synthesis of Silicon-Stereogenic Dibenzosiloles via Enantioselective $\mathrm{C}-\mathrm{H}$ Bond Functionalization $\mathrm{J}$. Am. Chem. Soc. 2012, 134, 7305-7308.

20. Shimizu, M.; Mochida, K.; Hiyama, T. Modular Approach to Silicon-Bridged Biaryls: Palladium-Catalyzed Intramolecular Coupling of 2-(Arylsilyl)aryl Triflates Angew. Chem. Int. Ed. 2008, 47, 9760-9764.

21. (a) Hu, A.; Ngo, H. L.; Lin, W. Remarkable 4,4'-Substituent Effects on Binap: Highly Enantioselective Ru Catalysts for Asymmetric Hydrogenation of $\beta$-Aryl Ketoesters and Their Immobilization in Room-Temperature Ionic Liquids Angew. Chem. 2004, 116, 2555-2558. (b) Hu, A.; Ngo, H. L.; Lin, W. 4,4'-Disubstituted BINAPs for Highly Enantioselective Ru-Catalyzed Asymmetric Hydrogenation of Ketones Org. Lett. 2004, 6, 2937-2940.

22. Sato, Y.; Takagi, C.; Shintani, R.; Nozaki, K. Palladium-Catalyzed Asymmetric Synthesis of Silicon-Stereogenic 5,10-Dihydrophenazasilines via Enantioselective 1,5-Palladium Migration Angew. Chem. Int. Ed. 2017, 56, 9211-9216.

23. Lin, Y.; Ma, W.-Y.; Xu, Z.; Zheng, Z.-J.; Cao, J.; Yang, K.-F.; Cui, Y.-M.; Xu, L.-W. Desymmetrization-Oriented Enantioselective Synthesis of Silicon-Stereogenic Silanes by Palladium-Catalyzed C-H Olefinations Chem. Asian J. 2019, 14, 2082-2085.

24. Huang, C.; Chattopadhyay, B.; Gevorgyan, V. Silanol: A Traceless Directing Group for Pd-Catalyzed o-Alkenylation of Phenols J. Am. Chem. Soc. 2011, 133, 12406-12409.

25. Shi, B.-F.; Maugel, N.; Zhang, Y.-H.; Yu, J.-Q. Pd ${ }^{\mathrm{II}}$-Catalyzed Enantioselective Activation of $\mathrm{C}\left(\mathrm{sp}^{2}\right)-\mathrm{H}$ and $\mathrm{C}\left(\mathrm{sp}^{3}\right)-\mathrm{H}$ Bonds Using Monoprotected Amino Acids as Chiral Ligands Angew. Chem. Int. Ed. 2008, 47, 4882-4886.

26. (a) Kuninobu, Y.; Yamauchi, K.; Tamura, N.; Seiki, T.; Takai, K. Rhodium-Catalyzed Asymmetric Synthesis of Spirosilabifluorene Derivatives Angew. Chem. Int. Ed. 2013, 52, 15201522. (b) Ureshino, T.; Yoshida, T.; Kuninobu, Y.; Takai, K. Rhodium-Catalyzed Synthesis of Silafluorene Derivatives via Cleavage of Silicon-Hydrogen and Carbon-Hydrogen Bonds J. Am. Chem. Soc. 2010, 132, 14324-14326.

27. Murai, M.; Takeuchi, Y.; Yamauchi, K.; Kuninobu, Y.; Takai, K. Rhodium-Catalyzed Synthesis of Chiral Spiro-9-silabifluorenes by Dehydrogenative Silylation: Mechanistic Insights into the Construction of Tetraorganosilicon Stereocenters Chem. Eur. J. 2016, 22, 6048-6058.

28. Murai, M.; Takeshima, H.; Morita, H.; Kuninobu, Y.; Takai, K. Acceleration Effects of Phosphine Ligands on the Rhodium-Catalyzed Dehydrogenative Silylation and Germylation of Unactivated C $\left(\mathrm{sp}^{3}\right)-\mathrm{H}$ Bonds J. Org. Chem. 2015, 80, 5407-5414.

29. Zhang, Q.-W.; An, K.; Liu, L.-C.; Zhang, Q.; Guo, H.; He, W. Construction of Chiral Tetraorganosilicons by Tandem Desymmetrization of Silacyclobutanes/Intermolecular Dehydrogenative Silylation Angew. Chem. Int. Ed. 2017, 56, 1125-1129.

30. (a) Tanaka, Y.; Yamashita, H.; Tanaka, M. Palladium- and Platinum-Catalyzed Reactions of Silacyclobutanes with Acid Chlorides Affording Cyclic Silyl Enol Ethers and/or 3(Chlorosilyl)propyl Ketones Organometallics 1996, 15, 1524-1526. (b) Chauhan, B. P. S.; Tanaka, Y.; Yamashita, H.; Tanaka, M. Palladium-Catalysed Three-Component Coupling Reactions of Dimethylsilacyclobutane, Carbon Monoxide and Organic Halides: a Convenient Route to Cyclic Silyl Enol Ethers Chem. Commun. 1996, 1207-1208. (c) Hirano, K.; Yorimitsu, H.; Oshima, K. Nickel-Catalyzed Reactions of Silacyclobutanes with Aldehydes: Ring Opening and Ring Expansion Reaction Org. Lett. 2006, 8, 483-485. (d) Hirano, K.; Yorimitsu, H.; Oshima, 
K. Nickel-Catalyzed Regio- and Stereoselective Silylation of Terminal Alkenes with Silacyclobutanes: Facile Access to Vinylsilanes from Alkenes J. Am. Chem. Soc. 2007, 129, 6094-6095. (e) Hirano, K.; Yorimitsu, H.; Oshima, K. Palladium-Catalyzed Formal Cycloaddition of Silacyclobutanes with Enones: Synthesis of Eight-Membered Cyclic Silyl Enolates Org. Lett. 2008, 10, 2199-2201. (f) Hatanaka, Y.; Watanabe, M.; Onozawa, S.-y.; Tanaka, M.; Sakurai, H. Rhodium-Catalyzed Insertion of Carbenoids into $\beta \mathrm{C}-\mathrm{H}$ Bonds of Silacycloalkanes: A Facile and General Approach to Functionalized Silacycloalkanes J. Org. Chem. 1998, 63, 422-423. (g) Shintani, R.; Moriya, K.; Hayashi, T. Palladium-Catalyzed Enantioselective Desymmetrization of Silacyclobutanes: Construction of Silacycles Possessing a Tetraorganosilicon Stereocenter J. Am. Chem. Soc. 2011, 133, 16440-16443.

31. (a) Pradere, U.; Garnier-Amblard, E. C.; Coats, S. J.; Amblard, F.; Schinazi, R. F. Synthesis of Nucleoside Phosphate and Phosphonate Prodrugs Chem. Rev. 2014, 114, 9154-9218. (b) Montchamp, J.-L., Phosphorus Chemistry I: Asymmetric Synthesis and Bioactive Compounds. Top. Curr. Chem. Springer International Publishing, 2015; Vol. 360. (c) Peruzzini, M.; Gonsalvi, L., Phosphorus Compounds: Advanced Tools in Catalysis and Material Sciences. Catalysis by Metal Complexes Springer Netherlands, 2011; Vol. 37.

32. (a) Börner, A., Phosphorus Ligands in Asymmetric Catalysis: Synthesis and Applications. Wiley-VCH, Weinheim, 2008; Vol. 1-3. (b) Dalko, P. I., Comprehensive Enantioselective Organocatalysis: Catalysts, Reactions, and Applications. Wiley-VCH, Weinheim, 2013; Vol. 1-3. 33. Denmark, S. E.; Beutner, G. L. Lewis Base Catalysis in Organic Synthesis Angew. Chem. Int. Ed. 2008, 47, 1560-1638.

34. Parmar, D.; Sugiono, E.; Raja, S.; Rueping, M. Complete Field Guide to Asymmetric BINOL-Phosphate Derived Brønsted Acid and Metal Catalysis: History and Classification by Mode of Activation; Brønsted Acidity, Hydrogen Bonding, Ion Pairing, and Metal Phosphates Chem. Rev. 2014, 114, 9047-9153.

35. (a) Grabulosa, A., P-Stereogenic Ligands in Enantioselective Catalysis. RSC Catalysis Series Royal Society of Chemistry, 2011; Vol. 7. (b) Tang, W.; Zhang, X. New Chiral Phosphorus Ligands for Enantioselective Hydrogenation Chem. Rev. 2003, 103, 3029-3070.

36. (a) Korpiun, O.; Lewis, R. A.; Chickos, J.; Mislow, K. Synthesis and Absolute Configuration of Optically Active Phosphine Oxides and Phosphinates J. Am. Chem. Soc. 1968, 90, 4842-4846. (b) Bergin, E.; O'Connor, C. T.; Robinson, S. B.; McGarrigle, E. M.; O'Mahony, C. P.; Gilheany, D. G. Synthesis of P-Stereogenic Phosphorus Compounds. Asymmetric Oxidation of Phosphines under Appel Conditions J. Am. Chem. Soc. 2007, 129, 9566-9567.

37. (a) Harvey, J. S.; Gouverneur, V. Catalytic Enantioselective Synthesis of $P$-stereogenic Compounds Chem. Commun. 2010, 46, 7477-7485. (b) Huang, Y.; Li, Y.; Leung, P.-H.; Hayashi, T. Asymmetric Synthesis of $P$-Stereogenic Diarylphosphinites by Palladium-Catalyzed Enantioselective Addition of Diarylphosphines to Benzoquinones J. Am. Chem. Soc. 2014, 136, 4865-4868. (c) Toda, Y.; Pink, M.; Johnston, J. N. Brønsted Acid Catalyzed Phosphoramidic Acid Additions to Alkenes: Diastereo- and Enantioselective Halogenative Cyclizations for the Synthesis of $C$ - and P-Chiral Phosphoramidates J. Am. Chem. Soc. 2014, 136, 14734-14737. (d) del ÁguilaSánchez, M. A.; Navarro, Y.; García López, J.; Guedes, G. P.; López Ortiz, F. Synthesis of PStereogenic Diarylphosphinic Amides by Directed Lithiation: Transformation Into Tertiary Phosphine Oxides Via Methanolysis, Aryne Chemistry and Complexation Behaviour Toward Zinc(II) Dalton Trans. 2016, 45, 2008-2022. (e) Huang, Z.; Huang, X.; Li, B.; Mou, C.; Yang, S.; Song, B.-A.; Chi, Y. R. Access to $P$-Stereogenic Phosphinates via $N$-Heterocyclic CarbeneCatalyzed Desymmetrization of Bisphenols J. Am. Chem. Soc. 2016, 138, 7524-7527. 
38. Du, Z.-J.; Guan, J.; Wu, G.-J.; Xu, P.; Gao, L.-X.; Han, F.-S. Pd(II)-Catalyzed Enantioselective Synthesis of P-Stereogenic Phosphinamides via Desymmetric C-H Arylation $J$. Am. Chem. Soc. 2015, 137, 632-635.

39. Guan, J.; Wu, G.-J.; Han, F.-S. Pd(II)-Catalyzed Mild C-H ortho Arylation and Intramolecular Amination Oriented by a Phosphinamide Group Chem. Eur. J. 2014, 20, 33013305.

40. Chen, Y.-H.; Qin, X.-L.; Guan, J.; Du, Z.-J.; Han, F.-S. Pd-Catalyzed Enantioselective C$\mathrm{H}$ Arylation of Phosphinamides with Boronic Acids for the Synthesis of $P$-stereogenic Compounds Tetrahedron: Asymmetry 2017, 28, 522-531.

41. Lin, Z.-Q.; Wang, W.-Z.; Yan, S.-B.; Duan, W.-L. Palladium-Catalyzed Enantioselective $\mathrm{C}-\mathrm{H}$ Arylation for the Synthesis of P-Stereogenic Compounds Angew. Chem. Int. Ed. 2015, 54, 6265-6269.

42. Pedroni, J.; Cramer, N. TADDOL-Based Phosphorus(III)-Ligands in Enantioselective Pd(0)-Catalysed C-H Functionalisations Chem. Commun. 2015, 51, 17647-17657.

43. Liu, L.; Zhang, A.-A.; Wang, Y.; Zhang, F.; Zuo, Z.; Zhao, W.-X.; Feng, C.-L.; Ma, W. Asymmetric Synthesis of $P$-Stereogenic Phosphinic Amides via $\operatorname{Pd}(0)$-Catalyzed Enantioselective Intramolecular C-H Arylation Org. Lett. 2015, 17, 2046-2049.

44. $\quad \mathrm{Xu}, \mathrm{G}$.; Li, M.; Wang, S.; Tang, W. Efficient Synthesis of P-Chiral Biaryl Phosphonates by Stereoselective Intramolecular Cyclization Org. Chem. Front. 2015, 2, 1342-1345.

45. Tang, W.; Capacci, A. G.; Wei, X.; Li, W.; White, A.; Patel, N. D.; Savoie, J.; Gao, J. J.; Rodriguez, S.; Qu, B.; Haddad, N.; Lu, B. Z.; Krishnamurthy, D.; Yee, N. K.; Senanayake, C. H. A General and Special Catalyst for Suzuki-Miyaura Coupling Processes Angew. Chem. Int. Ed. 2010, 49, 5879-5883.

46. Lin, Y.; Ma, W.-Y.; Sun, Q.-Y.; Cui, Y.-M.; Xu, L.-W. Catalytic Synthesis of Chiral Phosphole Oxides via Desymmetric C-H Arylation of $o$-Bromoaryl Phosphine Oxides Synlett 2017, 28, 1432-1436.

47. Li, Z.; Lin, Z.-Q.; Yan, C.-G.; Duan, W.-L. Pd-Catalyzed Asymmetric C-H Bond Activation for the Synthesis of P-Stereogenic Dibenzophospholes Organometallics 2019.

48. Gwon, D.; Park, S.; Chang, S. Dual Role of Carboxylic Acid Additive: Mechanistic Studies and Implication for the Asymmetric C-H Amidation Tetrahedron 2015, 71, 4504-4511.

49. Gwon, D.; Lee, D.; Kim, J.; Park, S.; Chang, S. Iridium(III)-Catalyzed C-H Amidation of Arylphosphoryls Leading to a P-Stereogenic Center Chem. Eur. J. 2014, 20, 12421-12425.

50. David, L.; Keith, F. Overview of the Mechanistic Work on the Concerted MetallationDeprotonation Pathway Chem. Lett. 2010, 39, 1118-1126.

51. Dieckmann, M.; Jang, Y.-S.; Cramer, N. Chiral Cyclopentadienyl Iridium(III) Complexes Promote Enantioselective Cycloisomerizations Giving Fused Cyclopropanes Angew. Chem. Int. Ed. 2015, 54, 12149-12152.

52. Jang, Y.-S.; Dieckmann, M.; Cramer, N. Cooperative Effects between Chiral Cp ${ }^{\mathrm{x}}-$ Iridium(III) Catalysts and Chiral Carboxylic Acids in Enantioselective $\mathrm{C}-\mathrm{H}$ Amidations of Phosphine Oxides Angew. Chem. Int. Ed. 2017, 56, 15088-15092.

53. Jang, Y.-S.; Woźniak, Ł.; Pedroni, J.; Cramer, N. Access to P- and Axially Chiral Biaryl Phosphine Oxides by Enantioselective Cp ${ }^{\mathrm{x} I r}{ }^{\mathrm{III}}-$ Catalyzed C-H Arylations Angew. Chem. Int. Ed. 2018, 57, 12901-12905.

54. Liu, Z.; Wu, J.-Q.; Yang, S.-D. Ir(III)-Catalyzed Direct C-H Functionalization of Arylphosphine Oxides: A Strategy for MOP-Type Ligands Synthesis Org. Lett. 2017, 19, 5434 5437. 
55. Hayashi, T. Chiral Monodentate Phosphine Ligand MOP for Transition-Metal-Catalyzed Asymmetric Reactions Acc. Chem. Res. 2000, 33, 354-362.

56. (a) Sun, Y.; Cramer, N. Rhodium(III)-Catalyzed Enantiotopic C-H Activation Enables Access to P-Chiral Cyclic Phosphinamides Angew. Chem. Int. Ed. 2017, 56, 364-367. (b) Park, S.; Seo, B.; Shin, S.; Son, J.-Y.; Lee, P. H. Rhodium-catalyzed oxidative coupling through C-H activation and annulation directed by phosphonamide and phosphinamide groups Chem. Commun. 2013, 49, 8671-8673.

57. (a) Satoh, T.; Miura, M. Oxidative Coupling of Aromatic Substrates with Alkynes and Alkenes under Rhodium Catalysis Chem. Eur. J. 2010, 16, 11212-11222. (b) Song, G.; Wang, F.; $\mathrm{Li}, \mathrm{X} . \mathrm{C}-\mathrm{C}, \mathrm{C}-\mathrm{O}$ and $\mathrm{C}-\mathrm{N}$ Bond Formation via Rhodium(III)-Catalyzed Oxidative $\mathrm{C}-\mathrm{H}$ Activation Chem. Soc. Rev. 2012, 41, 3651-3678.

58. (a) Ye, B.; Cramer, N. Chiral Cyclopentadienyl Ligands as Stereocontrolling Element in Asymmetric C-H Functionalization Science 2012, 338, 504-506. (b) Ye, B.; Cramer, N. A Tunable Class of Chiral Cp Ligands for Enantioselective Rhodium(III)-Catalyzed C-H Allylations of Benzamides J. Am. Chem. Soc. 2013, 135, 636-639. (c) Ye, B.; Cramer, N. Chiral Cyclopentadienyls: Enabling Ligands for Asymmetric $\mathrm{Rh}$ (III)-Catalyzed $\mathrm{C}-\mathrm{H}$ Functionalizations Acc. Chem. Res. 2015, 48, 1308-1318. (d) Newton, C. G.; Kossler, D.; Cramer, N. Asymmetric Catalysis Powered by Chiral Cyclopentadienyl Ligands J. Am. Chem. Soc. 2016, 138, 3935-3941. 59. Sun, Y.; Cramer, N. Tailored Trisubstituted Chiral $\mathrm{Cp}^{\mathrm{x}} \mathrm{Rh}^{\mathrm{III}}$ Catalysts for Kinetic Resolutions of Phosphinic Amides Chem. Sci. 2018, 9, 2981-2985.

60. (a) Ozols, K.; Jang, Y.-S.; Cramer, N. Chiral Cyclopentadienyl Cobalt(III) Complexes Enable Highly Enantioselective 3d-Metal-Catalyzed C-H Functionalizations J. Am. Chem. Soc. 2019, 141, 5675-5680. (b) Audic, B.; Wodrich, M. D.; Cramer, N. Mild Complexation Protocol for Chiral $\mathrm{Cp}^{\mathrm{x}} \mathrm{Rh}$ and Ir Complexes Suitable for in situ Catalysis Chem. Sci. 2019, 10, 781-787. 61. Definition $s$-value: $\mathrm{s}=\ln [(1-\mathrm{c})(1-\mathrm{ee})] / \ln [(1-\mathrm{c})(1+\mathrm{ee})]$ (c: conversion; ee: recovered substrate's ee).

62. (a) Lücking, U.; Jautelat, R.; Krüger, M.; Brumby, T.; Lienau, P.; Schäfer, M.; Briem, H.; Schulze, J.; Hillisch, A.; Reichel, A.; Wengner, A. M.; Siemeister, G. The Lab Oddity Prevails: Discovery of Pan-CDK Inhibitor (R)-S-Cyclopropyl-S-(4-\{[4-\{[(1R,2R)-2-hydroxy-1methylpropyl]oxy\}-5-(trifluoromethyl)pyrimidin-2-yl]amino phenyl)sulfoximide

(BAY 1000394) for the Treatment of Cancer ChemMedChem 2013, 8, 1067-1085. (b) Dillard, R. D.; Yen, T. T.; Stark, P.; Pavey, D. E. Synthesis and Blood Pressure Lowering Activity of 3(Substituted-Amino)-1,2,4-Benzothiadiazine 1-Oxide Derivatives J. Med. Chem. 1980, 23, 717722.

63. Sirvent, J. A.; Lücking, U. Novel Pieces for the Emerging Picture of Sulfoximines in Drug Discovery: Synthesis and Evaluation of Sulfoximine Analogues of Marketed Drugs and Advanced Clinical Candidates ChemMedChem 2017, 12, 476-476.

64. Fernández, I.; Khiar, N. Recent Developments in the Synthesis and Utilization of Chiral Sulfoxides Chem. Rev. 2003, 103, 3651-3706.

65. Trost, B. M.; Rao, M. Development of Chiral Sulfoxide Ligands for Asymmetric Catalysis Angew. Chem. Int. Ed. 2015, 54, 5026-5043.

66. (a) Gries, J.; Krüger, J. A Practical Approach to $N$-(Trifluoroacetyl)sulfilimines Synlett 2014, 25, 1831-1834. (b) Koji, M.; Fumio, T. Optical Resolution of Sulfoximines by Complex Formation with Optically Active 2,2'-Dihydroxy-1,1'-binaphthyl or 1,6-Di(o-chlorophenyl)-1,6diphenylhexa-2,4-diyne-1,6-diol Chem. Lett. 1988, 17, 1997-2000. (c) Allenmark, S.; Bomgren, B. Direct Liquid Chromatographic Separation of Enantiomers on Immobilized Protein Stationary 
Phases: II. Optical Resolution of a Sulphoxide, a Sulphoximine and a Benzoylamino Acid $J$. Chromatogr. A 1982, 252, 297-300.

67. (a) Dong, S.; Frings, M.; Cheng, H.; Wen, J.; Zhang, D.; Raabe, G.; Bolm, C. Organocatalytic Kinetic Resolution of Sulfoximines J. Am. Chem. Soc. 2016, 138, 2166-2169. (b) Wang, J.; Frings, M.; Bolm, C. Iron-Catalyzed Imidative Kinetic Resolution of Racemic Sulfoxides Chem. Eur. J. 2014, 20, 966-969.

68. Zhu, Y.-C.; Li, Y.; Zhang, B.-C.; Zhang, F.-X.; Yang, Y.-N.; Wang, X.-S. PalladiumCatalyzed Enantioselective C-H Olefination of Diaryl Sulfoxides through Parallel Kinetic Resolution and Desymmetrization Angew. Chem. Int. Ed. 2018, 57, 5129-5133.

69. (a) Sun, Y.; Cramer, N. Enantioselective Synthesis of Chiral-at-Sulfur 1,2-Benzothiazines by $\mathrm{Cp}^{\mathrm{x}} \mathrm{Rh}^{\mathrm{III}}-\mathrm{Catalyzed} \mathrm{C}-\mathrm{H}$ Functionalization of Sulfoximines Angew. Chem. Int. Ed. 2018, 57, 15539-15543. (b) Shen, B.; Wan, B.; Li, X. Enantiodivergent Desymmetrization in the Rhodium(III)-Catalyzed Annulation of Sulfoximines with Diazo Compounds Angew. Chem. Int. Ed. 2018, 57, 15534-15538.

70. Brauns, M.; Cramer, N. Efficient Kinetic Resolution of Sulfur-Stereogenic Sulfoximines by Exploiting $\mathrm{Cp}^{\mathrm{X}} \mathrm{Rh}^{\mathrm{III}}$-Catalyzed $\mathrm{C}-\mathrm{H}$ Functionalization Angew. Chem. Int. Ed. 2019, 58, 89028906.

\section{Table of Contents Graphic}

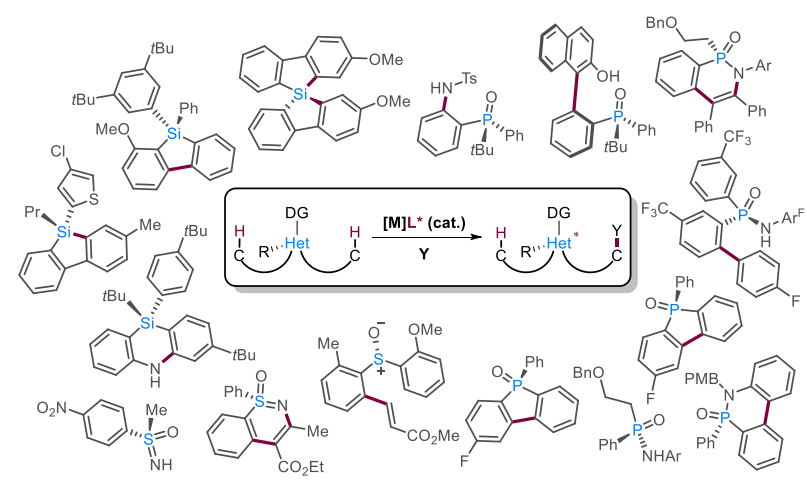

